\title{
Two-Photon Imaging of Stroke Onset In Vivo Reveals That NMDA-Receptor Independent Ischemic Depolarization Is the Major Cause of Rapid Reversible Damage to Dendrites and Spines
}

\author{
Timothy H. Murphy, ${ }^{1,2,3 \star}$ Ping Li, ${ }^{1 \star}$ Kellen Betts, ${ }^{1}$ and Richard Liu ${ }^{1}$ \\ ${ }^{1}$ Kinsmen Laboratory, Department of Psychiatry, ${ }^{2}$ Brain Research Center, and ${ }^{3}$ Department of Cellular and Physiological Sciences, University of British \\ Columbia, Vancouver, British Columbia, Canada V6T 1Z3
}

\begin{abstract}
We adapt a mouse global ischemia model to permit rapid induction of ischemia and reperfusion in conjunction with two-photon imaging to monitor the initial ionic, structural, and functional implications of brief interruptions of blood flow $(6-8 \mathrm{~min})$ in vivo. After only 2-3 min of global ischemia, a wide spread loss of mouse somatosensory cortex apical dendritic structure is initiated during the passage of a propagating wave $(3.3 \mathrm{~mm} / \mathrm{min})$ of ischemic depolarization. Increases in intracellular calcium levels occurred during the wave of ischemic depolarization and were coincident with the loss of dendritic structure, but were not triggered by reperfusion. To assess the role of NMDA receptors, we locally applied the antagonist MK-801 [(+)-5-methyl-10,11-dihydro-5H-dibenzo[a,d]cyclohepten-5,10-imine maleate] at concentrations sufficient to fully block local NMDA agonist-evoked changes in intracellular calcium levels in vivo. Changes in dendritic structure and intracellular calcium levels were independent of NMDA receptor activation. Local application of the non-NMDA glutamate receptor antagonist $\mathrm{CNQX}$ also failed to block ischemic depolarization or rapid changes in dendrite structure. Within 3-5 min of reperfusion, damage ceased and restoration of synaptic structure occurred over 10-60 min. In contrast to a reperfusion promoting damage, over this time scale, the majority of spines and dendrites regained their original structure during reperfusion. Intrinsic optical signal imaging of sensory evoked maps indicated that reversible alteration in dendritic structure during reperfusion was accompanied by restored functional maps. Our results identify glutamate receptor-independent ischemic depolarization as the major ionic event associated with disruption of synaptic structure during the first few minutes of ischemia in vivo.
\end{abstract}

Key words: anoxia; calcium; dendrite; dendritic spine; hypoxia-ischemia; imaging

\section{Introduction}

Although synapses may be a target of ischemia (Hasbani et al., 2001; Zhang et al., 2005), the sequence of ionic and electrical events that conspire to damage synaptic circuitry and potentially lead to cell death have been difficult to resolve in vivo with current stroke models and macroscopic imaging approaches (Kastrup et al., 2000; Biernaskie et al., 2001). Previous work implicates a variety of different mechanisms in the demise of neurons and their synaptic networks during ischemia, including ischemic depolarization, excitotoxic $\left[\mathrm{Ca}^{2+}\right]_{\mathrm{i}}$ changes, nonselective ion channels,

Received April 24, 2007; accepted Dec. 27, 2007.

This work was supported by Canadian Institutes of Health Research Operating Grant MOP49586 (T.H.M.) and grants from the Canadian Stroke Network and the Heart and Stroke Foundation of British Columbia and the Yukon. T.H.M. is a Michael Smith Foundation for Health Research Senior Scholar. We thank Dr. Kenneth G. Baimbridge for suggesting the bilateral common carotid model, Pumin Wang for outstanding animal surgeries, Charles Wang for help with data analysis, Shengxiang Zhang for assistance in preliminary experiments, and Kenneth G. Baimbridge, Lynn Raymond, and Craig Brown for comments on this manuscript.

*T.H.M. and P.L. contributed equally to this work.

Correspondence should be addressed to Dr. Timothy H. Murphy, Department of Psychiatry, University of British Columbia, 4N1-2255 Wesbrook Mall, Vancouver, British Columbia, Canada V6T 1Z3. E-mail: thmurphy@interchange.ubc.ca.

DOI:10.1523/JNEUROSCI.5128-07.2008

Copyright $\odot 2008$ Society for Neuroscience $\quad$ 0270-6474/08/281756-17\$15.00/0 membrane breakdown, and reperfusion injury (Silver and Erecinska, 1990, 1992; Nedergaard and Hansen, 1993; Hossmann, 1996; Kaminogo et al., 1998; Lee et al., 1999; Joshi and Andrew, 2001; Aarts et al., 2003; Hoyte et al., 2004; Xiong et al., 2004; Anderson et al., 2005; Thompson et al., 2006; Chuquet et al., 2007). Although a wealth of mechanistic data exists for in vitro simulated stroke, it is unclear whether the same mechanisms are at work in vivo, or how these events are related to structural and functional disruption of synaptic networks. When in vivo imaging was used previously to demonstrate loss of dendritic spines with ischemia, and their return during reperfusion (Zhang et al., 2005), the photothrombotic model used did not permit controlled reperfusion or temporal resolution better than 20-30 min, nor did this study evaluate the mechanism of damage. To determine the events leading up to ischemia-induced changes in dendritic structure and their relation to brain function, we devised a mouse in vivo global ischemia model compatible with two-photon imaging in which we can titrate the duration of ischemia to within seconds and can rapidly alternate between the initiation of ischemia or reperfusion. The ability to rapidly reverse ischemia allows us to produce multiple ischemic episodes within the same animal, permitting us to focus on the initial 
reversible events associated with ischemia, and not necessarily later irreversible processes associated with cell death.

A central hypothesis in the stroke literature is that ischemiainduced energy failure leads to aberrant release of glutamate and overstimulation of its receptor channels triggering many of the acute effects of stroke (Lee et al., 1999). Here, using in vivo imaging we delineate the early ionic and structural events associated with brief global ischemia and examine their sensitivity to blockade of glutamate receptors. We show that apical dendrites of layer $\mathrm{V}$ cortical neurons undergo profound alterations in structure with global ischemia, and that the chief mechanism of dendritic blebbing and spine loss is a propagating ischemic depolarization that envelops the cortex 2-3 min after ischemic onset and occurs independently of ionotropic glutamate receptors.

\section{Materials and Methods}

Transgenic mice. We have studied a total of 59 adult male and two female (2-5 months of age) yellow fluorescent protein (YFP)-H and green fluorescent protein (GFP)-M transgenic mice (Feng et al., 2000), as well as fluorescence protein-negative C57BL/6 wild-type mice. C57BL6 YFP- and GFP-expressing transgenic mice ( $\mathrm{H}$ and $\mathrm{M}$ lines) (Feng et al., 2000) were bred at the University of British Columbia animal facilities. All experiments used urethane anesthesia as in (Zhang et al., 2005). Briefly, anesthesia was induced with intraperitoneal injection of urethane $(0.12 \% \mathrm{w} / \mathrm{w})$ and body temperature was maintained at $37 \pm 0.5^{\circ} \mathrm{C}$ using a heating pad and feedback regulation from a rectal temperature probe. A sufficient level of anesthesia was confirmed by the lack of a toe-pinch reflex, typically established within $90 \mathrm{~min}$ of the initial urethane injection and maintained with only minimal supplementation $(<10 \%$ of the initial urethane dose) for up to $8 \mathrm{~h}$ during experiments. Hydration was maintained by intraperitoneal injection of saline $(200-300 \mu \mathrm{l})$ with $20 \mathrm{~mm}$ glucose at 1-2 h intervals. The experimental protocols were approved by the University of British Columbia animal care committee and consistent with Canadian Council on Animal Care and Use guidelines.

Surgical procedure and imaging. The surgical procedures for preparing a cranial window and the in vivo two-photon imaging methods have been described previously (Zhang et al., 2005). Briefly, animals were fitted into a custom-made head hold. Two-photon excitation was performed with a Coherent Mira 900 Ti-sapphire laser pumped by a $5 \mathrm{~W}$ Verdi laser and tuned to $900-920 \mathrm{~nm}$ to excite YFP or GFP. The cortex was covered with $1.3 \%$ low-melt agarose (at $37-38^{\circ} \mathrm{C}$; Type 3-A; A9793; Sigma, St. Louis, MO) dissolved in HEPES-buffered artificial CSF (ACSF) and sealed with a glass coverslip (\#1) as in (Zhang et al., 2005). In experiments with propidium iodide and NMDA pressure injection with Alexa 594, the laser was tuned to $810 \mathrm{~nm}$. Images were acquired by custom software (Igor) and by using an Olympus (Tokyo, Japan) IR-LUMPlanFl waterimmersion objective [ $40 \times, 0.8$ numerical aperture (NA)]. For in vivo time-lapse imaging of dendritic structure, multiple $z$-series were taken at 1-3 min time intervals. After reperfusion, stacks were taken less frequently to avoid potential laser damage. To ensure that the best optical conditions were present for spine imaging, most images of dendrites were taken within the first $70 \mu \mathrm{m}$ of cortex where the dendrites of layer $\mathrm{V}$ neurons project laterally (layer I). The images were taken with a pixel size of $0.2 \mu \mathrm{m}$, typically spanning a $205 \times 205 \mu \mathrm{m}$ area, and were the average of three frames taken over $5.5 \mathrm{~s}$. Occlusion was confirmed by in vivo two-photon imaging of blood flow as described previously (Zhang et al., 2005); blood plasma was labeled through a tail-vein injection of a $0.1 \mathrm{ml}$ bolus of $5 \%(\mathrm{w} / \mathrm{v})$ Texas-Red (TR) dextran (70 kDa; Invitrogen, Eugene, OR) in PBS.

To test of whether changes in detection or disposition of GFP or YFP protein could account for the apparent changes in structure, we examined the integrated (GFP or YFP) fluorescence over ischemic tissues. We observed a relatively small reversible decrease ( $31 \pm 5 \% ; n=3$ animals) in total fluorescence when dendrites underwent an abrupt shape change during global ischemia. The change in integrated signal was likely caused by changes in tissue light scattering and/or ischemic $\mathrm{pH}$ effects on the proteins used to view the structure (Griesbeck et al., 2001). These relatively small reductions in intensity suggest that the change in dendrite shape we observe is not attributable to a dramatic loss of two-photon fluorescence signal or changes in optical properties (for more evidence, see Discussion).

Calcium imaging, propidium iodide, and blood flow. In vivo loading with the membrane permeable $\mathrm{Ca}^{2+}$ indicator Oregon Green BAPTA-1 AM (OGB-1 AM; Invitrogen) was performed by pressure injection (30-60 s, 5-10 psi; Picospritzer II; General Valve Corporation, Fairfield, $\mathrm{NJ}$ ) of a $0.2 \mu \mathrm{m}$ filtered $0.8 \mathrm{mg} / \mathrm{ml}$ OGB-1 AM (with $6.7 \% \mathrm{DMSO} / 1.3 \%$ pluronic) containing ACSF solution with Alexa 594 as a tracer $(40 \mu \mathrm{M})$ into the somatosensory cortex using the protocol described by Stosiek et al. (2003). The injection pipettes were $\sim 5-7 \mathrm{M} \Omega$ in resistance. The maintained presence of $\mathrm{Ca}^{2+}$ indicator within neurons was confirmed by two-photon imaging (of basal fluorescence) and by $\left[\mathrm{Ca}^{2+}\right]_{\mathrm{i}}$ elevation and lack of saturation using a second round of ischemia $\sim 2 \mathrm{~h}$ after the first (see Fig. 5). During the second round of ischemia a similarly strong increase in OGB-1 fluorescence (apparently reflecting changes in $\left.\left[\mathrm{Ca}^{2+}\right]_{\mathrm{i}}\right)$ was also observed during ischemic depolarization $(n=4$ animals). Remarkably, one animal showed an increase in OGB-1 fluorescence during a third round of ischemia, which was $3 \mathrm{~h}$ after the first induction and $1 \mathrm{~h}$ after the second. These findings are inconsistent with OGB-1 [molecular weight (MW), $919 \mathrm{~g} / \mathrm{mol}$ ] undergoing widespread efflux from cells. Although, strong increases in OGB-1 fluorescence were coincident with ischemic depolarization, we caution that quantitative comparisons of the magnitude of the signal changes are difficult to make across animals, given that single wavelength calcium probes used are not intended for quantitative purposes in vivo, because small changes in background fluorescence or other factors could affect relative changes in signal.

In $\mathrm{Ca}^{2+}$ imaging experiments, we used simultaneous imaging of OGB-1 and GFP or YFP (XFP) to assess $\left[\mathrm{Ca}^{2+}\right]_{i}$ and structure respectively within layer I. Although these fluorophores were detected within the same green channel, the fluorescent protein signal was confined to a relatively small area (for an example with lower GFP process density, see supplemental Fig. 3, available at www.jneurosci.org as supplemental material) and did not increase when the signal of OGB-1-labeled neuronal cell bodies (layer II) or layer I neuropil increased with ischemic depolarization. These findings (XFP signal not increasing) argue against a change in imaging conditions producing the abrupt elevation in OGB-1 fluorescence. Furthermore, to confirm that the sudden rise in OGB-1 fluorescence was not the result of nonspecific factors, we also monitored the fluorescence of Texas Red-labeled blood vessels at the same time and failed to observe any increase in its signal during ischemic depolarization and structural breakdown (data not shown).

For imaging of $\left[\mathrm{Ca}^{2+}\right]_{\mathrm{i}}$ or propidium iodide (PI) uptake a wider (up to $2-4 \mu \mathrm{m}) z$-spacing was used to capture both layer I dendrites and in some cases layer II neuronal cell bodies (imaging down to $240 \mu \mathrm{m}$ depth). PI (30-60 $\mu \mathrm{M})$ was pressure injected without OGB-1 using a similar procedure with Alexa 594 as a tracer, although no pluronic or DMSO was present. Red blood velocity was measured from frame scan images in which blood vessels were identified that were oriented parallel to the scanning axis as described previously (Schaffer et al., 2006).

IOS imaging. For intrinsic optical signal (IOS) imaging, a large craniotomy $\left(\sim 3 \times 3 \mathrm{~mm}^{2}\right)$ was performed as by Zhang and Murphy (2007) and imaging performed with a charge-coupled device camera (XC ST70; Sony, Tokyo, Japan). The cortical surface was illuminated by red and green sets of light-emitting diodes (LEDs) mounted around a microscope objective (or video lens) driven by a regulated direct current (DC) power supply (Circuit Test, Burnaby, British Columbia, Canada). The green LED light source was used for visualizing the surface of the cortex and pattern of vessels. The red LED light source (center at $635 \mathrm{~nm}$ ) was used for IOS imaging. For imaging of functional maps, the depth of focus was set to $200 \mu \mathrm{m}$ below the cortical surface. Image acquisition was performed using XCAPstandard version 2.2 imaging software (EPIX, Buffalo Grove, IL) through a $2.5 \times$ Zeiss (Oberkochen, Germany) Plan Neofluor 0.075 NA objective. In some cases a Dalsa (Waterloo, Ontario, Canada) M-60 Pantera 12-bit camera was used for IOS and was mounted on a 
video microscopy setup (or an Olympus BX 51 upright scope) that used a short focus front to front video lens system (Bonhoeffer and Grinvald, 1993). We typically imaged an area of $3.1 \times 2.3 \mathrm{~mm}$ with a pixel size of $4.1 \mu \mathrm{m}$. Each data collection session consisted of 10 trials taken at $20 \mathrm{~s}$ apart. During each trial, 50 control images were collected over $1.67 \mathrm{~s}$ and another 50 images were collected after limb stimulation. Eight-bit images in repeated trials were summed in 16 bits and then a 32-bit ratio image depicting changes in $635 \mathrm{~nm}$ reflectance after stimulation was created (integrated stimulated image from 0 to $1.5 \mathrm{~s}$ after stimulation divided by integrated baseline image from 0 to $1.5 \mathrm{~s}$ prestimulation). We typically performed $30-40$ stimulus trials before and after ischemia for a given time point. Limb stimulation was produced by a pencil lead glued to the skin of the contralateral paw under the control of a stereo speaker or piezoelectric device driven by an isolated pulse stimulator (Model 2100; A-M Systems, Everett, WA). Vibrotactile stimuli were delivered at $100 \mathrm{~Hz}$ for $1 \mathrm{~s}$. The image acquisition, limb stimulation, and LED illumination were synchronized using TTL signals.

A 1 s long stimulus delivered to either the fore or hind limb resulted in a biphasic IOS lasting several seconds (supplemental Fig. 1, available at www.jneurosci.org as supplemental material). The signal consisted of scattered (reflected) light derived from illuminating the cortex with a $635 \mathrm{~nm}$ light emitting diode array ( $\sim 30 \mathrm{~nm}$ half width). At $1.5 \mathrm{~s}$ after stimulation the signal changed from a deflection (local deoxygenation) to a positive-going increase in scattered light apparently attributed to a general increase in blood flow (supplemental Fig. 1 , available at www.jneurosci.org as supplemental material). The late signal was not necessarily forelimb or hindlimb specific. Using interleaved trials (typically 20-40 stimulus presentations per limb), we produced maps of local somatosensory function in animals before and after ischemia by restricting our analysis to the first $1.5 \mathrm{~s}$ after limb stimulation.

VSD imaging. A craniotomy was made as described above and voltage-sensitive dye (VSD) RH-1692 (Optical Imaging, New York, NY) (Shoham et al., 1999) (concentration adjusted by optical density to 3-6 OD units) was dissolved in HEPES-buffered ACSF and applied for $90 \mathrm{~min}$ to label the cortex that lacked overlying dura. Forelimb, hindlimb, or null stimulation trials were taken every $10 \mathrm{~s}$. Data were analyzed by frame by frame division of averaged forelimb or hindlimb stimulation trials by the null trial data to correct for bleaching. Illumination was performed using a single red LED (Luxeon K2, $627 \mathrm{~nm}$ ) and fluorescence filter set as outlined previously (Ferezou et al., 2006) with an Olympus XLfluor $4 \times 0.28$ NA objective focused $200 \mu \mathrm{m}$ below the surface and imaged with a Dalsa $1 \mathrm{M} 60$ camera using a similar analysis as that used for IOS imaging.

Global ischemia model. For surgery the mouse was placed on its back and we put a $1 \mathrm{ml}$ syringe under its neck to expose the trachea. A small amount of a local anesthetic (50 $\mu$ l of lidocaine, s.c.) was injected into the neck region before making an incision over the thyroid gland. The thyroid and associated musculature and connective tissue were carefully dissected away from the trachea. The common carotid arteries were separated from the vagus nerves and muscles using blunt forceps. A suture (5-0, silk; Ethicon, Somerville, NJ) was looped around each common carotid artery (CCA) and then the 2 sets of suture loops were crossed in an $\mathrm{X}$ pattern across the trachea. The $\mathrm{X}$ pattern helps to give the sutures something to pull against. The area around the CCAs and looped sutures was then moistened using saline solution. Using two stitches, the incision was closed with the looped sutures pulled through a space in the skin to allow access and tensioning during imaging. The animal was turned upright and placed on an imaging frame and the craniotomy procedure performed. During two-photon imaging, ischemia was monitored using video microscopy of surface blood flow or by electroencephalogram (EEG) depression. To induce ischemia, we carefully pulled on both sutures and secured them with tape. Reperfusion was induced by removing the tension on the sutures. Preliminary Doppler blood-flow measurements indicated that this procedure was sufficient to produce a $>90 \%$ reduction in cortical blood flow within seconds of tensioning fine sutures placed around each CCA (data not shown). Consistent with the model having a widespread impact, we observed a significant slowing of the heart rate if CCA ligation was prolonged for $>8 \mathrm{~min}$, and in some cases within $6-7 \mathrm{~min}$. To avoid compromising the health of the animals we limited the ischemic period to $6-8 \mathrm{~min}$ (average $6.7 \pm 0.2 \mathrm{~min}$ ) and initiated reperfusion earlier if the heart rate slowed significantly (see above).

EEG recording. For EEG recording, a Teflon coated silver wire $(0.125$ $\mathrm{mm}$; World Precision Instruments, Sarasota, FL) was placed on the surface of the cortex within the agarose. A reference electrode was placed on the nasal bone under the skin. In some animals we used a reference electrode placed over the animal's back between the scapula. The cortical signal was amplified and filtered $(0.1-1000 \mathrm{~Hz})$ using a differential alternating current (AC) amplifier (Model 1700, A-M Systems) and digitized $(1000 \mathrm{~Hz})$ using a 1322A Digidata (Molecular Devices, Sunnyvale, CA). Additional off-line filtering of $10-20 \mathrm{~Hz}$ low pass was also performed routinely to resolve slow ischemic depolarization. The EEG was also used to define the point of ischemic onset by examining when ischemia was sufficient to suppress the spontaneous EEG; in our hands this occurred within tens of seconds of physically occluding the vessels. EEG data were collected using Clampex 8 and analyzed using Clampfit 8 or 9 (Molecular Dynamics). For recording of DC potentials we used a DAM 50 amplifier (World Precision Instruments) using Teflon-coated chlorided silver wires $(0.125 \mathrm{~mm}$ in diameter, $<1 \mathrm{~mm}$ of tip stripped by heating) placed as described above, and using a second reference electrode placed on the paw (filter set at $0.1-1000 \mathrm{~Hz}$ ).

In some cases, an AC amplifier was used to record ischemic depolarization. This amplifier measures a rippling slow waveform corresponding to an AC-filtered DC shift. To confirm that the slow AC EEG waves triggered by ischemia were coincident a depolarizing DC shift in cortical potential (relative hyperpolarization of extracellular space), we recorded from a subset of animals fitted with both AC and DC electrodes. We observed good correspondence between the ischemic onset and the latency to both slow AC and DC waveforms ( $115 \pm 5 \mathrm{~s}$ and $115 \pm 7 \mathrm{~s}$ for DC and AC recording, respectively, $n=3$ ischemic trials) (data not shown). To confirm that the ischemic depolarization was a synchronous depolarizing wave, we fitted some animals with two cortical electrodes several $\mathrm{mm}$ apart and observed excellent correspondence between them indicating that the signal we observed on the EEG was the average response of a very large cortical area and reflects synchronous activity. Synchrony between electrodes is not unexpected given we have implanted the electrodes within the freely conductive agarose overlying the brain. In some animals, we used a reference electrode placed over the animal's back between the forelimbs and also observed a fast contaminating signal on the EEG associated with the heartbeat. To confirm that the heart beat artifact was not altering cortical EEG activity, we also used another ground location over the nasal bone. In two animals where two different reference electrodes were used and data collected with the two grounding locations simultaneously (on two different channels), we obtained excellent correspondence in the slow waves indicating that the reference electrode position and cardiac artifact did not complicate interpretation of EEG results (data not shown). The embedded heart rate artifact allowed us to assess the cardiovascular fitness of animals subjected to global ischemia models. In most animals studied we observed a relatively normal heart beat of $\sim 400-600$ beats per min (Appleton et al., 2004) during preischemic periods that usually was not altered during global ischemia. In some animals, we did observe slowing of the heart rate after ischemic onset which in some cases became more pronounced, resulting in the death of $\sim 20 \%$ of animals.

In addition to measuring the heart rate electrophysiologically, we also assessed physiological parameters using a Starr Life Sciences (Oakmont, PA) Mouse-Ox pulse oximeter, mounted on the right hindlimb or the tail. Assessment of blood oxygen saturation (on average $>90 \%$ ) and heart rate $(400-600$ beats $/ \mathrm{min})$ in a subset of animals indicated that, under the conditions we used for imaging, physiological parameters were relatively constant over the course of our experiments. Bilateral CCA occlusion in some cases resulted in a reversible reduction of oxygen saturation $(<90 \%)$ that typically fully recovered within 5-10 min of reperfusion. All animals were under urethane anesthesia and were freely breathing air during monitoring and for all experiments.

Image analysis. Image analysis was performed using ImageJ soft- 
A

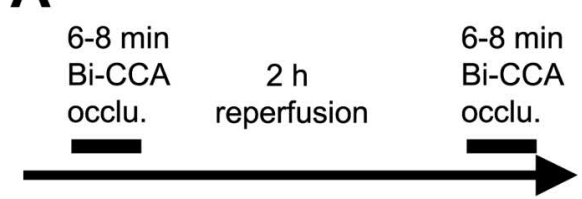

Assess blood flow, synapse structure, function, and electrical events.

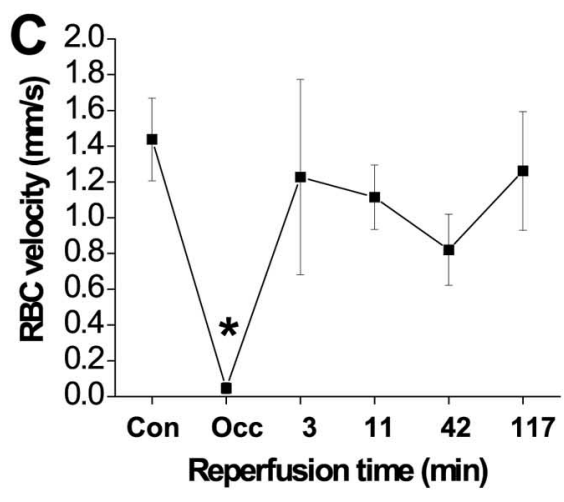

Figure 1. Common carotid artery occlusion reversibly blocks local cortical blood flow. $A$, Experimental schematic; $6-8$ min of bilateral CCA occlusion was produced by tensioning sutures placed around each artery while imaging, reperfusion was induced for up to $2 \mathrm{~h}$ by removing the tension, and in some animals a second round of CCA occlusion was performed. $\boldsymbol{B}$, Examples of two-photon imaging of blood flow using Texas Red-labeled plasma. Moving red blood cells create dark streaks across vessels as they are scanned. The angle of streaks in vessels that are oriented horizontally was used to determine velocity. Under control conditions two vessels are shown, the smaller of which is a capillary. Blood-flow velocity was calculated in millimeters per second, and negative values correspond to right-to-left flow. The inset shows a close up of streaking along the capillary used for blood flow velocity measurements. In the larger vessel, blood-flow direction has reversed and is now left to right, hence, positive values. The bottom image is a maximal intensity projection over $100 \mu \mathrm{m}$ of cortex showing vessels that are deeper. $C$, Group data from animals $(n=7)$ showing average red blood cell velocity for small vessels ( $4.3 \pm 0.2 \mu \mathrm{m}$ diameter) before, during CCA occlusion, and at various time points after. A one-way ANOVA indicated a significant reduction in velocity during occlusion ( ${ }^{*} p<0.05$ ).

ware (http://rsb.info.nih.gov/ij/). To reduce photon and photomultiplier tube noise, a median filter (radius, 1 pixel) was applied to all images. Spine counting and blood-flow measurements were done as described previously (Zhang et al., 2005). To assess dendritic blebbing after global ischemia, we estimated the fraction of blebbed dendrites by scoring $20 \mu \mathrm{m}$ dendritic segments observed in maximal intensity projections, as well as the $3 \mathrm{D}$ stack, as normal or blebbed for time points taken before, during, or after brief ischemia. Counting the segments was aided by the use of a grid with $20 \mu \mathrm{m}$ squares placed in ImageJ. Blebbed dendrites have regular swellings and have a "beads on string" appearance as described previously by Zhang et al. (2005) and investigators working in vitro and with histology (Hori and Carpenter, 1994; Park et al., 1996; Andrew et al., 2007). For the calculation of dendritic blebbing during occlusion, the last image stack taken before reperfusion was used. We scored dendrites as having blebs if they exhibited regularly spaced and rounded herniations that were punctuated by interbleb regions with lower, or in some cases nearly undetectable fluorescence. Blebbed regions were of larger diameter than their parent dendrite. These rounded structures were distinct from axonal boutons and passing dendrites cut in cross section that were observed in all animals prestroke and were checked by examining $3 \mathrm{D}$ stacks in addition to $z$-projections.

To quantify the IOS changes, video image stacks were imported and analyzed using custom written ImageJ plugins. To produce a color somatosensory response map, we thresholded the average ratio image (stimulated/control) to show the size of the functional map before and after ischemia. The threshold was based on $50 \%$ of maximal response derived from a smoothed line profile.

For statistical analyses that compare the difference between three or more groups, a one-way ANOVA was used with an $\alpha$ value for significance of 0.05 ; in cases where multiple post hoc comparisons were made, the Bonferroni's multiple comparison test was used. Comparison of two groups was made by $t$ test. Data are expressed as the mean $\pm \mathrm{SE}$, unless otherwise stated. IOS imaging responses were normalized to control values (i.e., forelimb stimulation in forelimb territory) and an ANOVA followed by Dunnet's multiple comparison post hoc tests were performed using Graphpad Prism. For post hoc IOS ANOVA testing, response amplitudes from all groups were tested versus nonspecific responses; either control forelimb-stimulus response recorded in the hindlimb area or control hindlimb-stimulus response recorded in the forelimb area were defined as nonspecific.

\section{Results}

A global ischemia model compatible with two-photon imaging

We first devised an ischemia model that could be rapidly and reproducibly used in conjunction with two-photon imaging to produce defined ischemic episodes with robust reperfusion (Fig. $1 A$ ). This procedure extends our previous focal ischemia models (Zhang et al., 2005; Zhang and Murphy, 2007), as well as irreversible cardiac arrest models used by others (Chuquet et al., 2007; Takano et al., 2007), by providing rapid induction of ischemia and controlled reperfusion. To accomplish this, we reversibly and bilaterally occluded the CCAs of adult urethane anesthetized C57/B16 mice. To quantify changes in blood flow elicited by CCA ligation, we used two-photon imaging (Fig. $1 A-C$ ) (Kleinfeld et al., 1998; Zhang et al., 2005; Nishimura et al., 2006; Schaffer et al., 2006). We measured red blood cell (RBC) velocity in small vessels on average $4.3 \pm 0.2 \mu \mathrm{m}$ in diameter (Fig. $1 B$ ). During occlusion, RBC velocity in the same vessels was reduced by $>95 \%$ ( $n=7$ animals). Removing tension on CCAs restored flow to $>75 \%$ of control levels within $10 \mathrm{~min}$ (Fig. 1C).

\section{A rapid and reversible loss of dendritic structure during global ischemia}

After establishing a model where reversible ischemia was produced during two-photon imaging, we sought to determine its impact on dendrite and spine structure in layer $\mathrm{V}$ neuron apical tufts (Fig. 2A-C). Dendritic structure was quantified within the first $100 \mu \mathrm{m}$ of cortex in 16 XFP transgenic mice where both ischemia and reperfusion was confirmed (78\% of dendrites exhibited blebs at the last time point before reperfusion) (for group data, see Fig. $2 B$ ). The loss of structure was characterized by a blebbing of dendrites and a loss of a significant fraction of spines (Fig. 2A,C, supplemental Movie 1, available at www.jneurosci.org as supplemental material). Although the dendritic swelling was severe, careful inspection of $3 \mathrm{D}$ stacks revealed that most 
spines were still present on blebbed dendrites; on average $\sim 30 \%$ of spines were transiently lost (Fig. $2 A, C$ ).

To compensate for small ischemiainduced changes in focus and/or dendrite warping, all dendrites were imaged using $z$-stacks of $\sim 20-30 \mu \mathrm{m}$ of layer I cortex taken at $\sim 1-3$ min intervals. Spine turnover was always assessed by examining 3D stacks. As evidence that optical changes were not a major factor in the loss of spines and structure, we observed that other labeled structures, such as blood vessels filled with TR dextran, did not undergo significant degradation in resolution during ischemia (Figs. $1 B, 3 E)$. Analysis of labeled capillaries indicated that during CCA occlusion their diameter was relatively unaffected $(4.9 \pm 0.2 \mu \mathrm{m}$ preischemia vs $4.6 \pm 0.2 \mu \mathrm{m}$ during occlusion; $n=14$ vessels), despite dendrites around them becoming markedly swollen.

After $\sim 6-8 \mathrm{~min}$ of ischemia, reperfusion was initiated by loosening tension on the CCAs and blood flow quickly returned (Fig. $1 C)$. Under these conditions, we observed a return of relatively normal dendritic structure over 30-60 $\mathrm{min}$, with some animals even showing some recovery within $10 \mathrm{~min}$ of reperfusion (Fig. $2 A$ ). When reperfusion was initiated, dendrites and spines appeared to regain their initial structure with lost spines reappearing at the same sites and exhibiting similar structure (Figs. 2A, C, 3E, $5 B)$. In 7 of 14 animals in which reversible ischemia was induced and recovery examined after $>1 \mathrm{~h}$, we observed a nearly complete return of dendritic structure after the first round of ischemia (recovered to $10 \%$ or less blebbed dendrites). Analysis of individual spines in 10 animals (with a lower density of XFP-labeled neurons) indicated that on average $\sim 30 \%$ of spines were lost during both the 6-8 min period of occlusion and first $13.8 \pm 1.4 \mathrm{~min}$ of reperfusion (Fig. $2 C$ ). To simplify matters, we assessed the recovery of spines at a long time point (averaged 87 min after ischemia induction) and found that most had recovered. Interestingly, $6.0 \pm$ $2.4 \%$ of spines observed under control conditions could not be found at $\sim 80 \mathrm{~min}$ after ischemia (Fig. $2 C$ ) ( $n=8$ animals). We have assessed rates of spine turnover in mice not subject to CCA occlusion and recovery using an identical craniotomy preparation and anesthesia and find that spine loss over an even longer period of $6 \mathrm{~h}$ in the same region of cortex was significantly lower and only $0.19 \pm 0.023 \% ; n=6$ animals, $p<0.05 t$ test (Brown et al., 2007). A second round of ischemia ( $\sim 2 \mathrm{~h}$ after the first) also led to reversible dendritic damage and spine loss. In five animals in which second rounds of ischemia were given and recovery was followed for $>60$ min (for both ischemic episodes), we observed a significantly more dendritic beading after $60 \mathrm{~min}$ of recovery from the second round of
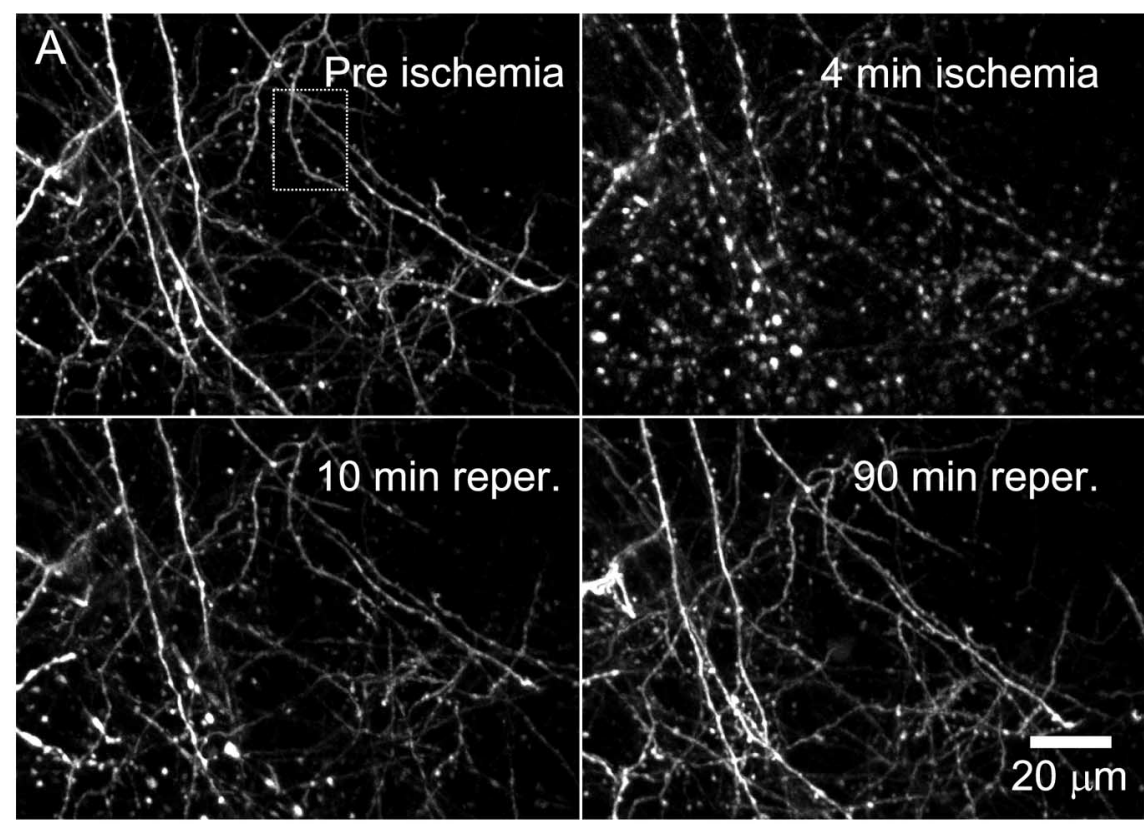

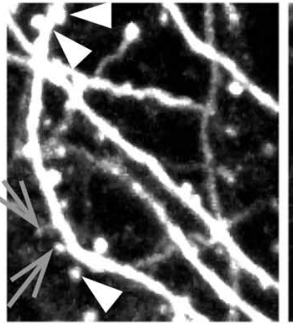

Control

B

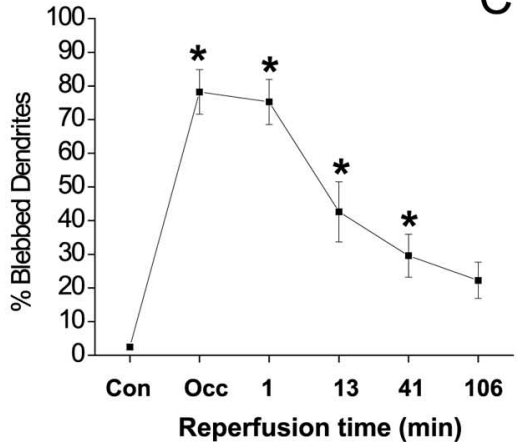

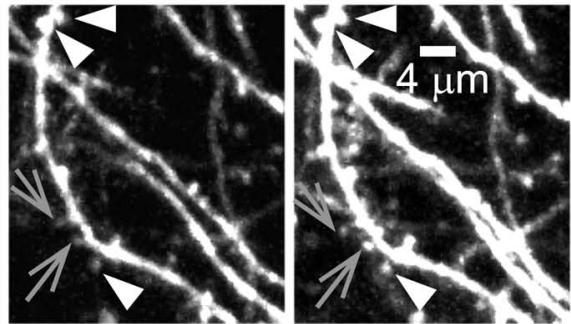

10 min reper
Figure 2. Reversible loss of spiny dendritic structure during bilateral carotid artery occlusion. $\boldsymbol{A}$, Maximal intensity projection images of layer $V$ neuron tuft dendrites (maximal intensity projection image) before and $4 \mathrm{~min}$ after ischemia and various time points during reperfusion. The white-boxed area in the top left corresponds to a region in close up images shown in the close-up panel below. Bottom, Close-up views of top panels; white arrowheads show the location of dendritic spines present throughout the ischemia/reperfusion; larger gray arrows indicate transiently lost spines. $\boldsymbol{B}$, Average percentage of blebbed dendrites during CCA occlusion and the indicated average times of reperfusion. All changes in blebbed dendrite percentages were significantly different from control except for 106 min of reperfusion (by one-way ANOVA, ${ }^{*} p<0.05$; data from $n=16$ different animals). $\boldsymbol{C}$, Group data showing changes in spine number relative to control preischemia conditions in 10 different animals during occlusion ( $n=711$ spines), $\sim 5$ min after reperfusion ( $n=801$ spines), $\sim 15$ min after reperfusion ( $n=310$ spines), and $\sim 80$ min reperfusion ( $n=688$ spines). A significant difference $\left({ }^{*} p<0.05\right)$ was observed between control and occlusion, control and $5 \mathrm{~min}$ reperfusion, and control and 14 min reperfusion (by one-way ANOVA).

ischemia (data not shown), suggesting an accumulation of ischemic damage with multiple episodes.

\section{Circuit function reverses with reperfusion}

To assess recovery of cortical circuit function we used somatosensory stimulus evoked IOS imaging (Bonhoeffer and Grinvald, 1993) (Fig. 3). These signals reflect hemodynamic re- 



Figure 3. Analysis of cortical function during reversible alteration in synaptic structure during ischemia. $A$, Composite video and two-photon images; background shows a low power view of the cortical surface vasculature produced by illuminating the cortex with green light. The inset shows a branched large vessel (area with white box around it) where two-photon imaging of both blood flow and dendrite structure were performed. The color composite image (red and green) on the right is of both dendrites (green) and vessels (red). Dendrites were found to undergo a reversible change in structure within this region (see $\boldsymbol{E}$ ). $\boldsymbol{B}$, Grayscale map derived from stimulating the contralateral hindlimb (HL); image represents the percentage change in $635 \mathrm{~nm}$ reflected light observed $0-1.5 \mathrm{~s}$ after limb stimulation. C, C', Color IOS response maps produced using a threshold based on $50 \%$ of the smoothed maximal response value. Areas responding to contralateral hindlimb stimulation are coded in green, whereas contralateral (FL)-responsive areas are coded in red. Before the ischemic onset, discrete hindlimb and territories can be observed. At an average time of $50 \mathrm{~min}$ after ischemia, both the hindlimb and maps have nearly recovered. An EEG recording electrode is also visible below the hindlimb area. $\boldsymbol{D}$, Analysis of group data indicate that a significant contralateral limb stimulated response returns for trials taken on average $0.75-2 \mathrm{~h}$ after ischemia ( $n=6$ animals). No significant $10 S$ responses were evoked for trials taken on average $15-45$ min after ischemia with either contralateral limb stimulus ( $n=4$ animals). No significant response was observed when the contralateral forelimb was stimulated and the IOS response quantified in hindlimb territory, or vice versa, indicating specificity. Responses were normalized to control (prestroke) contralateral forelimb and hindlimb responses in their respective territories. ( ${ }^{*} p<0.05$, one-way ANOVA). $\boldsymbol{E}$, Close-up view of dendrites and vessels from the area outlined in panel $A$ at the border of the hindlimb area showing intact dendritic and vessel structure during the first $2 \mathrm{~min}$ of ischemia (before ischemic depolarization). The next set of images was taken after ischemic depolarization ( 5 min after occlusion) and show extensive dendritic damage. The right-most panel shows structural recovery $1 \mathrm{~h}$ after reperfusion.

sponses that are stimulated by underlying neuronal activity. In six animals before ischemia, we found that movement of either the contralateral forelimb or hindlimb $(100 \mathrm{~Hz}, 1 \mathrm{~s}$ stimulus $)$ would produce a change in the IOS within the appropriate somatosensory cortex territory in which dendrites were also imaged using twophoton microscopy during reversible ischemia (Fig. $3 A-E$ ). After forelimb stimulation (over $1.5 \mathrm{~s}$ ), the reflected light signal within the forelimb area was reduced consistent with a local increase in deoxyhemoglobin associated with increased neuronal activity (supplemental Fig. 1, available at www.jneurosci.org as supplemental material) (Devor et al., 2003; Dunn et al., 2005).

Assessment of somatosensory stimulus evoked maps at time points averaging $0.75-2 \mathrm{~h}$ after ischemia ( $n=6$ animals) indicated that restored dendritic structure was associated with cortical function (Fig. $3 C, D)$. At $0.75-2 \mathrm{~h}$ after CCA ligation, map amplitudes were not significantly different when compared with preischemic controls, and the maps appeared to have the same general shape and dimensions (Fig. 3C,D). The presence of relatively normal maps at 0.75-2 $\mathrm{h}$ after CCA occlusion suggested that reperfusion was associated with normal activity-induced hemodynamic responses. A concern with IOS mapping is that hemodynamic responses may predominantly reflect presynaptic activity because previous data indicate that they are not reduced by antagonists of excitatory receptors in the olfactory bulb (Gurden et al., 2006). However, the olfactory bulb may be a unique case because it receives strong afferents and has relatively little intrinsic circuitry. Given rich intracortical circuits, we would expect the maps we observe (in particular in superficial layers where we monitor IOS) to be dependent on the disposition of postsynaptic circuits such as dendrites. Consistent with this proposal, we find that CNQX treatment (see Fig. $8 F, G$ ) completely suppressed both forelimb and hindlimb activity evoked IOS maps in three of three separate animals. In addition, the return of sensory-evoked IOS maps we observe (after reperfusion) correlates with the return of spontaneous EEG activity consistent recovery of both presynaptic and postsynaptic circuits (see below). To further examine this issue, in two animals using voltage sensitive dyes that directly measure sensory-evoked depolarization (Grinvald and Hildesheim, 2004; Ferezou et al., 2006), we confirmed that somatosensory cortex function was present 40-90 min after reperfusion (supplemental Fig. 2, available at www.jneurosci.org as supplemental

material).

To determine whether transient depression of IOS maps was observed just after CCA occlusion we produced maps within the first $45 \mathrm{~min}$ after ischemic onset by beginning stim- 
ulus trials as early as 6 min after reperfusion in four animals (Fig. 3D). As expected from analysis of structural data (where variability was highest during the first time points after reperfusion), considerable differences were observed in map function between animals at early time points after reperfusion. Some animals showed little or no map function up to $45 \mathrm{~min}$ after ischemic onset, whereas others had relatively normal maps at these early time points. Reversible depression of hindlimb sensory evoked maps was also observed using VSD imaging at these early time points (supplemental Fig. 2, available at www.jneurosci.org as supplemental material). Given this potential variability in early map recovery, and our requirement to average trials using interstimulus intervals of up to $20 \mathrm{~s}$, we have not performed an extensive analysis of IOS or VSD maps within $\sim 15$ min of reperfusion after CCA occlusion.

\section{Electroencephalogram alterations indicate a delayed ischemic depolarization}

Although we show reversal of structural and functional deficits with reperfusion, we had little insight into their initial triggers. In the example shown in Figure 4, $A$ and $B$, extensive damage occurs $\sim 3 \mathrm{~min}$ after the onset of ischemia and progresses over a period of seconds suggesting that rapid electrical events may lead to a wave of synchronous damage. To assess the mechanism by which rapid changes in dendritic structure occurred, we included AC and/or DC EEG electrodes within the agarose overlying the craniotomy (see Figs. $8 F, 9 A$ ). During periods of baseline activity in preischemic animals, we observed a robust regular EEG signal consisting of relatively low-frequency $\sim 1 \mathrm{~Hz}$ activity expected with urethane anesthesia (Fig. 4C) (Kerr et al., 2005). Bilateral CCA occlusion resulted in a rapid suppression of EEG activity within 10-20 s (Fig. 4C). Powerspectrum analysis indicated that EEG power (squared millivolts per hertz) in the $1 \mathrm{~Hz}$ range $(0.3-3 \mathrm{~Hz})$ was reduced by $>90 \%$. The average EEG power suppression within the first $20 \mathrm{~min}$ after ischemia was to $2 \pm 4 \%$ of preischemic values ( $n=7$ animals). Given these robust changes, the loss of a normal cortical EEG was used as a marker of ischemic onset (also confirmed using video imaging and two-photon imaging of blood flow).

In 20 animals studied by EEG (either AC or DC recordings), we observed slowly developing electrical activity that

\section{Pre-depolarization}

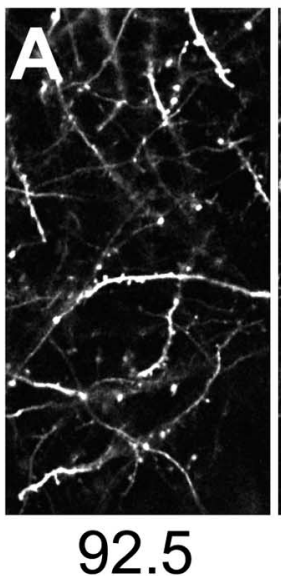

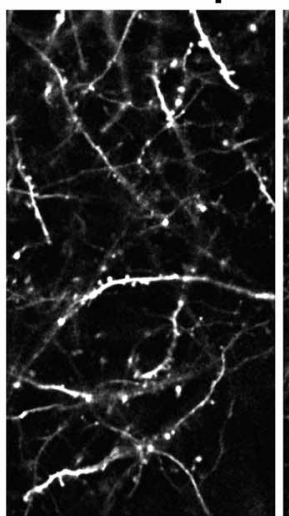

98
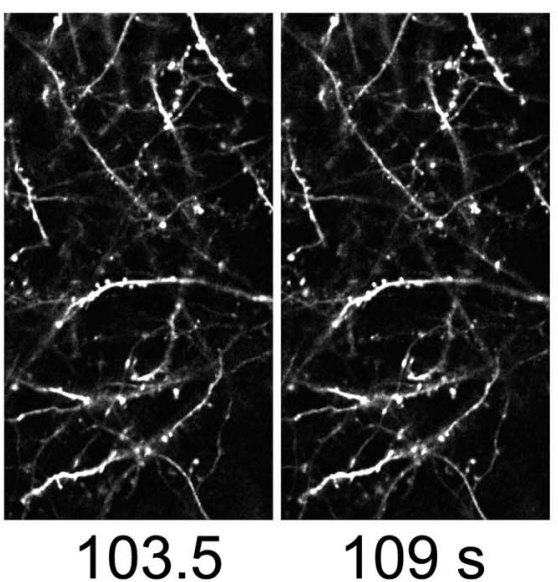
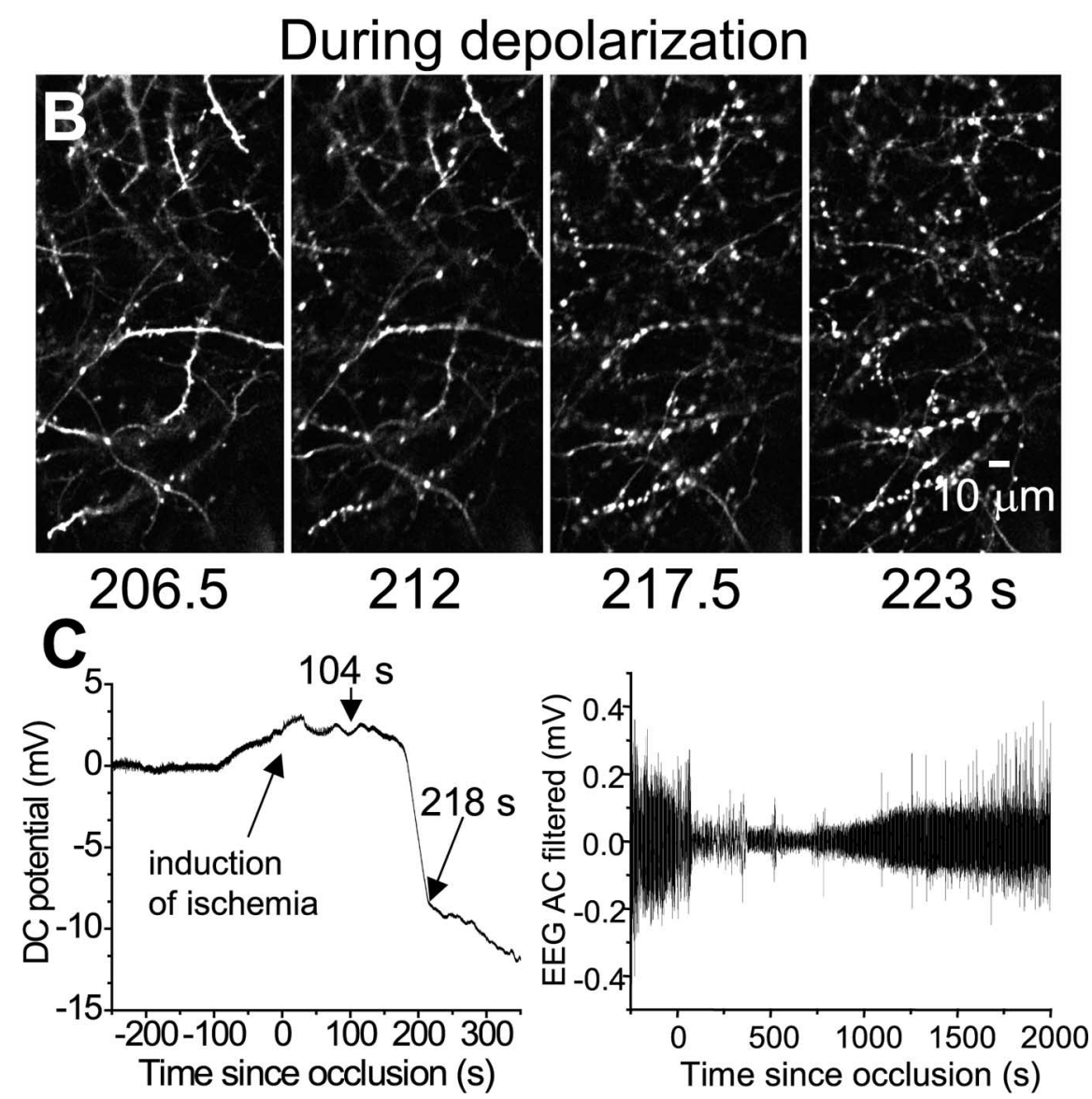

Figure 4. Changes in dendritic morphology occur synchronously over a period of seconds during global ischemia. A, Images shown are sequential $1 \mu \mathrm{m}$ sections of dendrites taken during z-sectioning through layer I. The sequence shown begins $92.5 \mathrm{~s}$ after occlusion of both (CAs and was taken before ischemic depolarization (C). Because of relatively poor z-resolution, oversampling results and some processes are viewed in multiple images taken $5.5 \mathrm{~s}$ apart. $\boldsymbol{B}$, Same region as in $\boldsymbol{A}$; a change in dendritic morphology occurs at $217.5 \mathrm{~s}$, just after the onset of a DC potential shift observed at $\sim 200 \mathrm{~s}$ after occlusion (C). Because the EEG electrodes sample a large area and the depolarization moves slowly across the brain $(\sim 3 \mathrm{~mm} / \mathrm{min})$, the EEG signal can occur before a local change in morphology is observed. $C$, Record of $D C$ cortical surface potential from the same animal as imaged in $A$ and $\boldsymbol{B}$. Left, A DC shift was observed $\sim 200 \mathrm{~s}$ after bilateral CCA occlusion. Right, AC filtered EEG record (0.1-10 Hz bandpass), indicating rapid suppression of the EEG during ischemia and return of spontaneous activity over a $20-30$ min period. was consistent with a shift in DC potential $(<0.1 \mathrm{~Hz})$ that appeared $109.79 \pm 11.0 \mathrm{~s}$ after the onset of electrical silence induced by CCA occlusion (Fig. 4C). The shift in DC potential with ischemia was reversible and returned to near baseline 


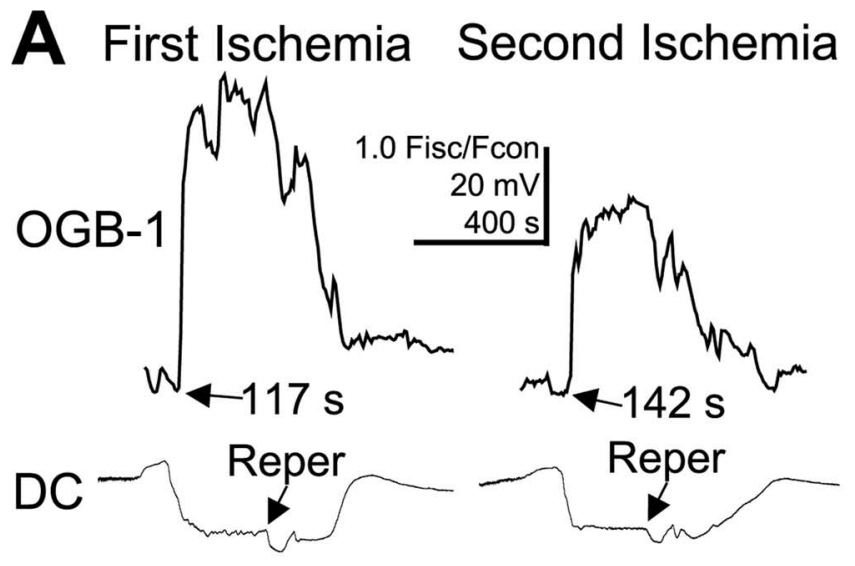

B First Ischemia
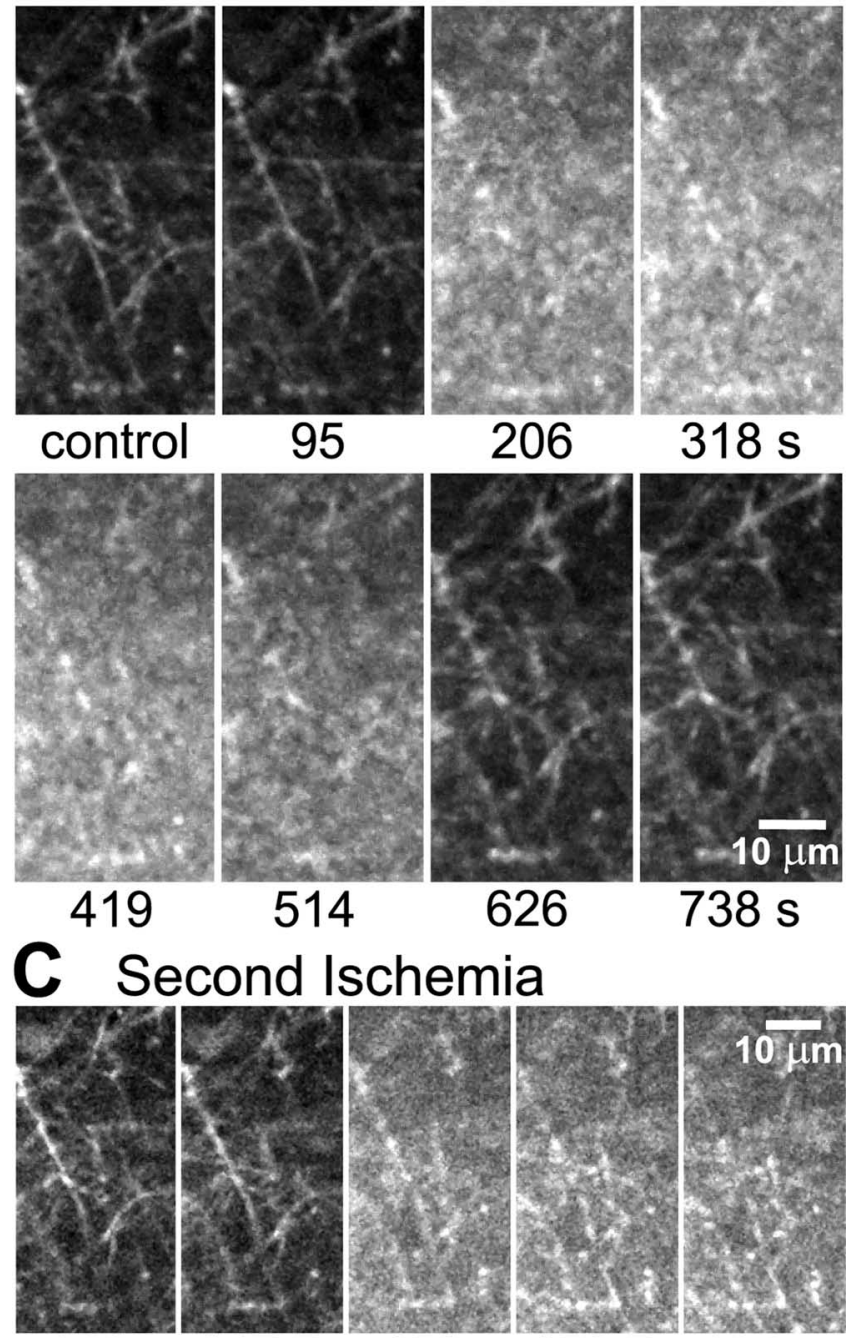

$738 \mathrm{~s}$

142
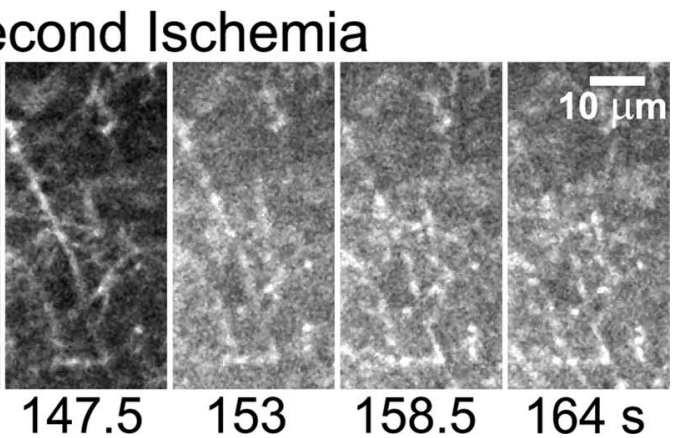

Figure 5. Changes in intracellular calcium in vivo during transient ischemia coincide with slow EEG activity and dendritic beading. $\boldsymbol{A}$, Change in normalized OGB-1 fluorescence taken from the neuropil in layer I cortex of an animal subjected to bilateral CCA ligation. To control for changes in fluorescence intensity with depth, the 0GB-1 fluorescence during ischemia was divided by that obtained just before the onset of ischemia using identical settings and laser power. On the same time scale, we plot the cortical DCEEG indicating that the change in OGB-1 fluorescence was coincident with ischemic depolarization. The ischemic episodes were within a single animal taken $\sim 2 \mathrm{~h}$ apart; both episodes showed an 0GB-1 fluorescence increase and ischemic depolarization after CCA occlusion. $\boldsymbol{B}$, Composite image showing GFP-labeled dendrites surrounded by diffuse OGB-1-labeled layer I neuropil from the same animal as the one
(67\% recovery) values after a $629 \pm 44$ s period of sustained depolarization ( $n=5$ ischemic trials in 4 animals) (Fig. $5 A$ ). This slow synchronous activity had temporal characteristics associated with previously described ischemic or anoxic depolarization (Ayad et al., 1994; Li et al., 2000). To avoid fluctuations in recording conditions associated with the handling of animals during CCA occlusion, we used AC coupled recordings or AC filtering ( $0.1-10 \mathrm{~Hz}$ bandpass) of DC potentials (Fig. 4C) to assess when ischemic electrical silence occurred. During reperfusion, we observed a return of relatively normal EEG activity (by comparison to preischemic power spectra) over a 20-60 min period (Fig. 4C), similar to the time required to observe consistent restoration of intrinsic optical signals produced by forelimb stimulation. In Figure $4 C$, the EEG amplitude can be roughly assessed from the thickness of the record shown. We assessed recovery of EEG power after reperfusion in seven animals and found that on average $39 \pm$ $30 \%$ returned $2 \mathrm{~h}$ after reperfusion (measured at $1 \mathrm{~Hz}$ ). This recovered EEG power at $2 \mathrm{~h}$ was similar in power spectrum to that observed in animals before ischemic treatment, and was depressed during a subsequent round of ischemia (data not shown). The reasons for the incomplete return in EEG amplitude after reperfusion are unclear, but it is important to consider that EEG amplitude reflects coherent activity and is not necessarily a reliable measure of the potential for synaptic activity. Conceivably, the incomplete return of EEG activity could also be attributed to ischemia-induced downregulation of AMPA receptors as observed previously by others in vitro (Ikegaya et al., 2001).

\section{Intracellular calcium elevation accompanies dendritic} damage and ischemic depolarization Relatively few studies have evaluated $\left[\mathrm{Ca}^{2+}\right]_{\mathrm{i}}$ during ischemia and reperfusion in vivo (Silver and Erecinska, 1992; Du et al., 2005). We extend this previous work by determining how $\left[\mathrm{Ca}^{2+}\right]_{\mathrm{i}}$ changes are temporally related to changes in cortical structure and function. To further investigate the mechanism of ischemic damage to dendrites we assessed intracellular $\left[\mathrm{Ca}^{2+}\right]_{\mathrm{i}}$ changes with the fluorescent indicator OGB-1AM (Fig. 5, supplemental Figs. 3, 4, available at www.jneurosci.org as supplemental material). Loading OGB-1 AM was by pressure injection $\sim 200 \mu \mathrm{m}$ below the cortical surface (Stosiek et al., 2003; Ohki et al., 2005; Winship et al., 2007). This procedure results in strong labeling of layer II neuron cell bodies that begin to be visible $\sim 100 \mu \mathrm{m}$ below the cortical surface. Above layer II and toward the cortical surface in layer I were a

shown in $\boldsymbol{A}$. Maximal intensity projections were made over $4 \mu \mathrm{m}$. Note that no 0GB-1-labeled glial or neuronal cell bodies were present here. At $206 \mathrm{~s}$ after ischemic onset and after ischemic depolarization (estimated to have occurred at $117 \mathrm{~s}$ ), the layer I neuropil shows a large increase in $0 G B-1$ fluorescence indicating a sudden rise in $\left[\mathrm{Ca}^{2+}\right]_{\mathrm{i}}$. At this time, the dendrites have become severely blebbed, seen over a uniform change in background neuropil 0GB-1 fluorescence. Note that because $z$-stacks were only taken every $2 \mathrm{~min}, 206 \mathrm{~s}$ was the earliest time point after ischemic depolarization with images of these laterally projecting dendrites. The images are of lower contrast because 0GB-1 labels the background neuropil. Two minutes after reperfusion (Reper; $514 \mathrm{~s}$ after occlusion), neuropil OGB-1 fluorescence levels are already beginning to decline and $13 \mathrm{~min}$ after ischemia the dendritic structure is nearly fully restored (738 s). C, Composite image showing GFP-labeled dendrites surrounded by diffuse 0GB-1-labeled layer I neuropil from the same animal as the one shown in $\boldsymbol{A}$ and $\boldsymbol{B}$ after the second period of ischemia. Sequential $1 \mu \mathrm{m}$ sections through the tissue are shown as in Figure $4 A$. At $153 \mathrm{~s}$ after CCA occlusion and after ischemic depolarization (occurs at $\sim 142 \mathrm{~s}$ ), the 0GB-1 fluorescence markedly increased in the layer I neuropil and the dendrites became suddenly blebbed indicating near coincidence between $\mathrm{Ca}^{2+}$ elevation and dendritic structural changes. 
few labeled astrocytes as well as diffuse labeling of passing fibers believed to be axons and dendrites of neurons in deeper layers (Kerr et al., 2005). Based on these findings, we have termed these diffuse OGB-1-labeled fibers the neuropil, and show that they can exhibit somatosensory stimuli-evoked $\mathrm{Ca}^{2+}$ elevations (Winship et al., 2007) with rapid kinetics distinct from slower glial $\mathrm{Ca}^{2+}$ transients (Nimmerjahn et al., 2004; Wang et al., 2006). Before ischemia, we averaged fluorescence over $5.5 \mathrm{~s}$ periods that were long enough to dampen any spontaneous $\mathrm{Ca}^{2+}$ dependent fluctuations in neuropil OGB-1 signal (Kerr et al., 2005). Because the layer I neuropil was where the XFP-labeled dendrites were located, we restricted our analysis of OGB-1 to this region. We have chosen to use OGB-1 (a green flurophore) despite overlap in emission with XFPs because we believe OGB-1 gives better neuronal signals than red calcium indicators. Another advantage of OGB-1 is its significant basal fluorescence that allowed us to confirm that effective dye loading had occurred. Importantly, we show that XFP fluorescence does not increase during ischemia (actually decreases, see Materials and Methods) and interfere with neuropil $\left[\mathrm{Ca}^{2+}\right]_{\mathrm{i}}$ measurements. It is acknowledged that the relatively high affinity of OGB-1 may not permit us to accurately estimate peak ischemic $\left[\mathrm{Ca}^{2+}\right]_{\mathrm{i}}$ because of its potential for saturation. However, our goal was to measure the timing of increases in $\left[\mathrm{Ca}^{2+}\right]_{i}$ with respect to dendritic structural alteration and not attempt to quantify $\left[\mathrm{Ca}^{2+}\right]_{\mathrm{i}}$ in vivo. Whereas lower affinity indicators may be more desirable for estimating peak $\left[\mathrm{Ca}^{2+}\right]_{\mathrm{i}}$, it is conceivable that they too may be saturated during ischemic depolarization because intracellular ion selective electrodes indicate $30 \mu \mathrm{M}$ $\left[\mathrm{Ca}^{2+}\right]_{\mathrm{i}}$ (Silver and Erecinska, 1992). Conversely, low affinity fluorescent indicators may be unable to pick relatively smaller changes in $\left[\mathrm{Ca}^{2+}\right]_{\mathrm{i}}$ during reperfusion.

In all ischemic episodes studied, and coincident with ischemic depolarization (assessed by either the AC ripple EEG signal or DC shift) we observed a sudden rise in $\left[\mathrm{Ca}^{2+}\right]_{\mathrm{i}}$ levels commencing $142.3 \pm 12.4 \mathrm{~s}(n=14$ ischemic trials in 11 different animals) after ischemic onset that was maintained for several hundred seconds $(451.3 \pm 60.1 \mathrm{~s}, n=7$ ischemic trials in 5 animals) (Fig. $5 A$ ). In the same animals that underwent abrupt elevations in $\left[\mathrm{Ca}^{2+}\right]_{\mathrm{i}}$ we observed slow changes on the EEG (either AC ripple or DC shift indicative of massive depolarization) that began $136.9 \pm 13.7 \mathrm{~s}$ after ischemic onset. The fact that the EEG changes began just before the abrupt change in $\left[\mathrm{Ca}^{2+}\right]_{\mathrm{i}}$ is not surprising because the large EEG electrodes were placed within the conductive agarose overlying the brain and would be expected to pick up signals first as the slow waves enter the craniotomy.

During reperfusion no additional abrupt elevations in $\left[\mathrm{Ca}^{2+}\right]_{\mathrm{i}}$ were observed in seven ischemic trials studied in separate five animals (we did not have reperfusion data on all animals). Fluorescence levels returned to near baseline values during reperfusion (Fig. $5 A, B$ ), suggesting that most of the $\mathrm{Ca}^{2+}$ dependent damaging events occurred during the initial 6-8 min of ischemia. It is conceivable that the observed reduction in fluorescence intensity during reperfusion could be attributable to leakage of the indicator from neurons or changes in imaging conditions and not $\left[\mathrm{Ca}^{2+}\right]_{\mathrm{i}}$ levels normalizing. To check that sustained indicator saturation or loss from cells did not account for the reversible nature of ischemia-evoked $\left[\mathrm{Ca}^{2+}\right]_{\mathrm{i}}$ transients we asked whether transients were repeatable within the same animal. The effects of ischemia on $\left[\mathrm{Ca}^{2+}\right]_{\mathrm{i}}$ levels were repeatable within the same animal during a second round of occlusion $\sim 2 \mathrm{~h}$ (increase in $\left[\mathrm{Ca}^{2+}\right]_{\mathrm{i}}$ observed in three animals) (Fig. $5 \mathrm{~A}, \mathrm{C}$, supplemental Fig. 4, available at www.jneurosci.org as supplemental material). During the second ischemic episode, the latency between the onset of ischemic depolarization and changes in OGB-1 fluorescence was also well preserved, consistent with ischemic depolarization being the cause of the abrupt $\mathrm{Ca}^{2+}$ increase (Fig. 5, supplemental Figs. 4, 6, available at www.jneurosci.org as supplemental material). The ability to produce multiple ischemia-induced $\left[\mathrm{Ca}^{2+}\right]_{\mathrm{i}}$ signals within the same animal suggests that OGB-1 does not leak appreciably from cells or remain saturated $\sim 2 \mathrm{~h}$ after occlusion and reperfusion. Furthermore, our results are consistent with intracellular ion sensitive microelectrodes used in the CA1 region in vivo where transient global ischemia induced $\left[\mathrm{Ca}^{2+}\right]_{\mathrm{i}}$ elevation could return to baseline within tens of minutes of reperfusion (Silver and Erecinska, 1992).

The observation that ischemic depolarization causes the largest and most abrupt increase in $\left[\mathrm{Ca}^{2+}\right]_{i}$ would suggest that this event is critical for altering the structure of synaptic circuits. Consistent with this proposal we observed changes in dendritic structure that were coincident with both the ischemic depolarization as measured by EEG activity and the elevation in $\left[\mathrm{Ca}^{2+}\right]_{\mathrm{i}}$ detected with OGB-1 dye (Fig. 5B,C). To assess this quantitatively we measured the average latency between the change in dendritic structure and the abrupt elevation in OGB-1 fluorescence signal to be $\sim 6 \mathrm{~s}$ with the elevation in $\left[\mathrm{Ca}^{2+}\right]_{\mathrm{i}}$ just preceding the change in structure $(5.5 \pm 1.3 \mathrm{~s}$ for $n=9$ ischemic trials in 7 animals) (supplemental Fig. 6, available at www.jneurosci.org as supplemental material).

\section{Rapid loss of synaptic structure and ischemic depolarization does not result from a loss of membrane integrity}

A concern mentioned previously is that leakage of $\mathrm{Ca}^{2+}$ indicator from cells resulting from membrane breakdown or permeability to nonselective ion channels (Thompson et al., 2006) may underlie the apparent decrease in layer I neuropil $\left[\mathrm{Ca}^{2+}\right]_{\mathrm{i}}$ signal observed during reperfusion. To better understand whether small molecule $\mathrm{Ca}^{2+}$ indicators are retained during and after ischemia, we have assessed membrane integrity during the rapid ischemia-induced deformation of dendrites by measuring the uptake of PI, a membrane impermeable nucleic acid stain. In four animals we evaluated the influx of PI into the somata of layer II neurons by preinjecting it into the imaging area 45-90 min before induction of ischemia. Layer V neuronal somata were too deep to reliably image after ischemia so we evaluated layer II cell bodies, which also send dendrites to layer I. We find that PI is retained extracellularly within healthy brain tissue and is largely nonfluorescent until it enters cells with permeable membranes and undergoes nucleic acid binding (Sun et al., 2006). Previous studies have shown that PI (MW, $414 \mathrm{~g} / \mathrm{mol}$ ) enters cells during membrane breakdown and through some gap junction type channels (Elfgang et al., 1995). Before ischemia, PI injection resulted in labeled dura and a few damaged neurons within layer II confirming that adequate dye was present. Induction of ischemia for 6-8 min produced characteristic EEG changes, but failed to cause any additional PI uptake and nucleic acid labeling, even 30-40 min after induction of ischemia $(n=4$ separate animals). However, at longer time points 60-90 min after ischemia, we observed that PI labeling of layer II neuron cell bodies was apparent (in two of four animals) (supplemental Fig. 5, available at www.jneurosci.org as supplemental mate- 
rial). The images shown were projected over $90 \mu \mathrm{m}$ of cortex so the total number of PI positive neurons in this large volume is actually relatively low. These results indicate permeability to polar tracers can occur at later time points, but does not contribute to rapid deterioration of dendritic structure observed minutes after global ischemia onset. Our results showing little permeability of membranes within $40 \mathrm{~min}$ of ischemia to low molecular weight dyes suggests that substances such as ATP and other intracellular constituents that appear extracellularly are not released through wide-spread loss of membrane integrity in vivo (Contreras et al., 2004). Perhaps, in vitro studies of ischemia showing increased membrane permeability (Thompson et al., 2006) model relatively later stage in vivo events that reflect delayed membrane breakdown (that we observe in some animals after $40 \mathrm{~min}$ ) and possibly precede cell death.

\section{The role of NMDA receptors}

The literature is divided on the role of NMDA-type glutamate receptors in ischemia. NMDA receptor antagonists have been implicated previously in ameliorating ischemic cell death, and can have robust effects in some in vivo and in vitro models (Lee et al., 1999; Hoyte et al., 2004; Simon, 2006). However, in vivo rodent global ischemia data (Corbett et al., 1990; Diemer et al., 1992; Olsson et al., 2003), as well as human clinical stroke trials (Lee et al., 1999; Hoyte et al., 2004; Simon, 2006) have been unable to indicate a clear causal role of these receptors under the conditions in which receptor antagonists were applied. Accordingly, we determined whether treatment with the NMDA receptor blocker (+)-5-methyl-10,11-dihydro-5Hdibenzo[a,d]cyclohepten-5,10-imine maleate (MK-801) would effect either the loss of dendritic structure or the elevation in $\left[\mathrm{Ca}^{2+}\right]_{\mathrm{i}}$ observed with OGB-1. To apply MK-801, we initially used intraperitoneal delivery $(5 \mathrm{mg} / \mathrm{kg} ; n=2)$ and observed no reduction in dendritic structural changes during bilateral CCA occlusion. Although MK-801 has been routinely administered by intraperitoneal injection (Corbett et al., 1990), we noticed that some animals given systemic MK-801 may have developed respiratory problems. Accordingly, we mostly used local application of MK-801 directly to the open craniotomy ( $300 \mu \mathrm{M} ; n=7$ animals) with a preincubation period as described previously to reduce systemic effects (Gurden et al., 2006); note a relatively high concentration was used because of expected dilution. To ensure continued delivery of MK- 801 it was also mixed $(30 \mu \mathrm{M})$ with the overlying agarose when it was cooling before application to the craniotomy.

\section{Positive controls for MK-801 action in vivo}

Although the doses and concentrations of MK-801 used would be expected to effectively block NMDA receptors, we nonetheless confirmed their actions in vivo. Confirmation of MK-801 action was performed using $\mathrm{Ca}^{2+}$ imaging. NMDA $500 \mu \mathrm{M}$ was applied by local pressure ejection in a red fluorescent Alexa 594 solution to confirm agonist ejection (Fig. 6A). Before MK-801 administration, robust NMDA-evoked calcium transients were observed within layer II neuronal cell bodies (present $\sim 100 \mu \mathrm{m}$ below the surface) and passing OGB-1labeled neuropil fibers (Fig. $6 \mathrm{~B}$ ). MK-801 addition by $30 \mathrm{~min}$ local infusion resulted in a complete blockade of the NMDA evoked response in 4 separate animals. To check that these treatments did not render neurons unresponsive to all elevations in $\left[\mathrm{Ca}^{2+}\right]_{\mathrm{I}}$, we also showed in the some animals that addition of a non-NMDA receptor dependent agonist such as

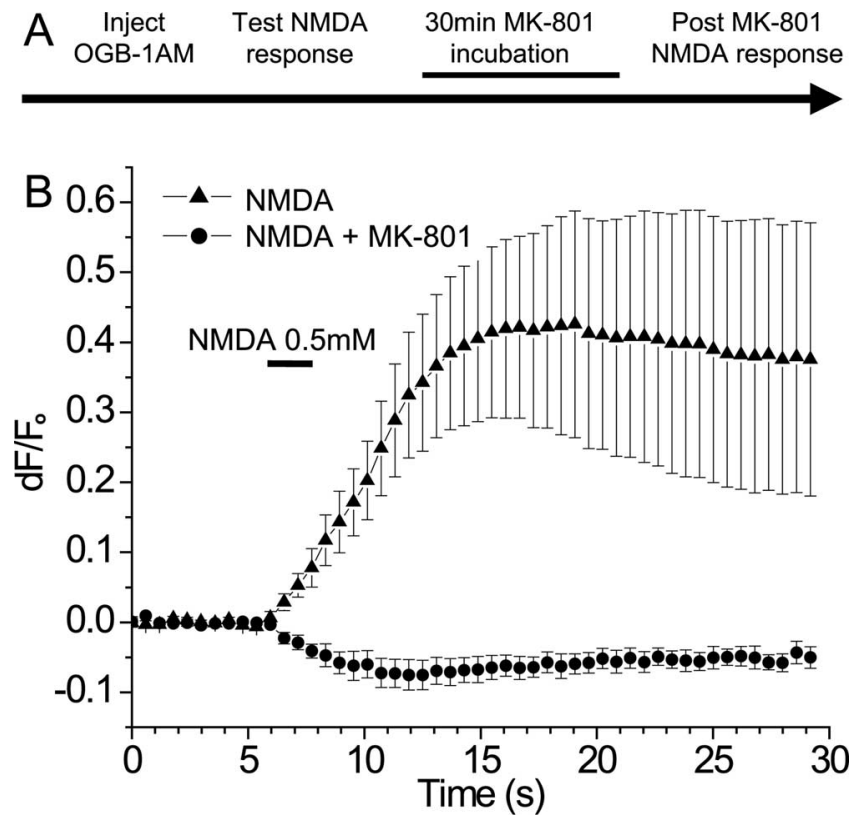

Figure 6. In vivo confirmation that MK-801 blocks layer I NMDA receptors. $\boldsymbol{A}$, Experimental schematic for in vivo confirmation of MK-801 effects. The 0GB-1 fluorescence responses to NMDA application were tested before and after locally applying MK-801 (300 $\mu$ m preincubation and $30 \mu \mathrm{m}$ in agarose) to the cortex. $\boldsymbol{B}$, Group data showing that $0 \mathrm{~GB}-1$ fluorescence changes $\left(\mathrm{df} / F_{0}\right)$ to NMDA application before and after MK-801 incubation. NMDA was applied by local pressure ejection ( $4 \mathrm{psi}$ ) for $\sim 2 \mathrm{~s}$ after $6 \mathrm{~s}$ from the start of imaging. There was a significant reduction in NMDA-evoked 0GB-1 fluorescence responses after MK-801 treatment ( $p<0.05$; $n=4$ animals). The data show that this concentration of MK-801 applied locally to cortex can block layer I NMDA receptors.

kainate (data not shown) could elicit a $\mathrm{Ca}^{2+}$ elevation. These data indicate that concentrations of MK-801 were sufficient to block NMDA receptors at cortical depths in excess of $100 \mu \mathrm{m}$. Given that dendritic structure and $\mathrm{Ca}^{2+}$ elevation was typically studied within the first $70 \mu \mathrm{m}$, we believe our pharmacological treatments are sufficient to fully block the NMDA receptor at the depths where imaging of dendrites were performed.

No reduction in dendritic damage, spine loss, or early changes in $\left[\mathrm{Ca}^{2+}\right]_{\mathrm{i}}$ in MK-801-treated animals

In the presence of MK-801, dendritic blebbing averaged $72 \%$ during occlusion and peak changes in neuropil OGB-1 fluorescence $\left(2.2 \pm 0.3 F_{\text {isch }} / F_{\text {con }}, n=10\right.$ control animals vs $2.0 \pm 0.2$ $n=4 \mathrm{MK}-801$ animals; $p>0.05$ ) were not significantly reduced by MK-801 versus untreated controls (Fig. 7, supplemental Movies 2, 3, available at www.jneurosci.org as supplemental material). The ability of dendrites to recover structure during reperfusion was also unaffected by MK-801 treatment (Fig. 7). Ischemic depolarization as assayed by DC EEG recordings still occurred and was of similar magnitude to that observed in the absence of MK$801(-15 \pm 1.1 \mathrm{mV}, n=8 \mathrm{MK}-801$, vs $-12 \pm 1.1 \mathrm{mV}, n=7$ control animals; $p>0.05)$.

\section{AMPA/kainate receptor antagonists do not affect dendritic blebbing or ischemic depolarization}

Previous studies indicate a role for the AMPA-type glutamate receptor in mediating ischemic damage both in vitro and in vivo (Sheardown et al., 1990, 1993; Buchan et al., 1991; Gaspary et al., 1994; Gressens et al., 2005). To determine the role of non-NMDA type ionotropic glutamate receptors in early ischemic changes in 

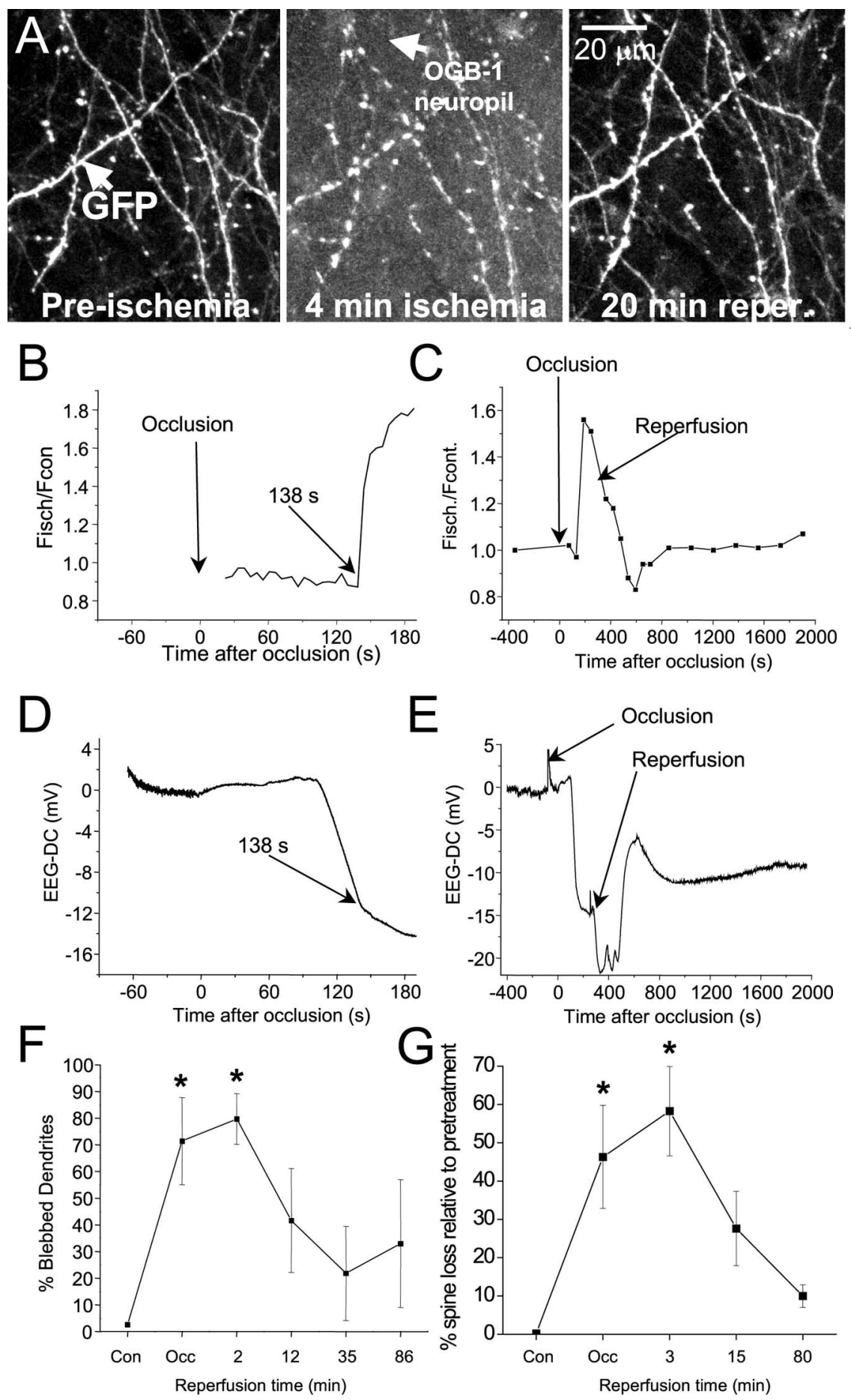

Figure 7. No effect of NMDA receptor blockade on ischemic depolarization, changes in $\left[\mathrm{Ca}^{2+}\right]$, or dendritic damage. $A$, Maximal intensity projection images $(10 \mu \mathrm{m})$ from an NMDAR-antagonist (MK-801, applied locally) treated mouse showing GFP-labeled spiny dendrites and OGB-1 fluorescence in layer I. The left image was taken before bilateral CCA occlusion. After occlusion (center image), an increase in neuropil fluorescence and disruption of dendritic structure was observed. After reperfusion (right image), a reduction of neuropil OGB-1 fluorescence and recovery of dendritic structure was observed. $B, C$, Quantification of neuropil OGB-1 fluorescence from the MK-801-treated animal in $\boldsymbol{A}$ over short $(\boldsymbol{B})$ and long $(\boldsymbol{C})$ time scales shows a rapid increase in neuropil fluorescence $140 \mathrm{~s}$ after occlusion of the CCAs. The ratio values in $\boldsymbol{B}$ were calculated for individual frames of a stack for neuropil regions of interest and divided by values for the same frames taken before ischemia (as in Fig. 5B). The graph in ( (slower time scale) was produced by averaging all neuropil fluorescence over each projected stack and dividing by a corresponding preischemia value. $\boldsymbol{D}, \boldsymbol{E}$, Cortical $D C$ potential recording from the same MK-801-treated animal on short $(\boldsymbol{D})$ and long $(\boldsymbol{E})$ time scales indicate that an ischemic depolarization occurs after occlusion of the CCAs. Recovery of the cortical DC potential was observed after reperfusion at $400 \mathrm{~s}$. Because of handling the animal during occlusion and reperfusion, sharp artifactual transients (near 0 and $300 \mathrm{~s}$ ) and shifts in baseline are observed during reperfusion. $\boldsymbol{F}$, Group data on percentage of blebbed dendrites $(n=5)$ in MK-801-treated animals. A significant difference $\left({ }^{*} p<0.05\right.$ by one-way ANOVA) was observed between control and occlusion, and control and 2 min reperfusion. $\mathbf{G}$, Group data showing changes in vivo, we used treatment with the competitive antagonist AMPA/kainate antagonist CNQX (Sheardown et al., 1990, 1993; Gressens et al., 2005) and assessed whether it would alter ischemia-induced depolarization and changes in dendrite structure (Fig. $8 A-D)$. We have chosen to use CNQX a competitive AMPA and kainate receptor antagonist because it is readily soluble in water allowing us to preload the brain with high concentrations. AMPA selective noncompetitive antagonists of 2,3-benzodiazepine structure such as 4-(8-methyl-9H-1,3dioxolo[4,5-h] [2,3]benzodiazepin-5-yl)benzenamine hydrochloride (GYKI 52466) have poor solubility making them difficult to apply in a concentrated manner. CNQX is also closely related and only twofold less potent than its analog NBQX. NBQX has been shown to reduce the effects of focal and global ischemia in vivo, at concentrations equal or lower than 2,3-benzodiazepines (Sheardown et al., 1990, 1993; Gressens et al., 2005). An advantage of using CNQX as an anti-excitotoxic drug is that it also potently blocks kainate receptors (more potent than NBQX), and also has some activity against glycine binding at NMDA receptors further increasing its neuroprotective potential (Sheardown et al., 1990).

We first established whether a similar treatment paradigm to MK-801 would give indications that AMPA/kainate receptors were blocked locally within somatosensory cortex in vivo. CNQX was preincubated at a concentration of $5 \mathrm{~mm}$ over an open craniotomy in an extracellular solution for 30 $\mathrm{min}$. To ensure sustained delivery of CNQX, we also included it within the agarose overlying the brain at $1 \mathrm{~mm}$. To determine whether CNQX effectively antagonized AMPA receptors in vivo, we measured spontaneous EEG activity that is expected to be dependent on AMPA-receptor depolarizations. Assessment of EEG power at $1 \mathrm{~Hz}$ indicated a reduction of $70 \pm 6 \%$ after CNQX treatment ( $n=7$ animals) (Fig. $8 B$ ). The observation that CNQX did not completely abolish EEG activity could be related to the use of relatively large surface electrodes that pick up signals from outside of the craniotomy where CNQX did not have access. Conversely, unblocked EEG activity during CNQX treatment

$\leftarrow$

spine number relative to control preischemia condition in 5 MK-801-treated animals during occlusion ( $n=625$ spines), $\sim 3$ min after reperfusion ( $n=620$ spines), $\sim 15$ min after reperfusion ( $n=461$ spines), and $\sim 80$ min after reperfusion ( $n=469$ spines). A significant difference $\left(^{*} p<0.05\right.$ by oneway ANOVA) was observed between control and occlusion, and control and 3 min reperfusion. 

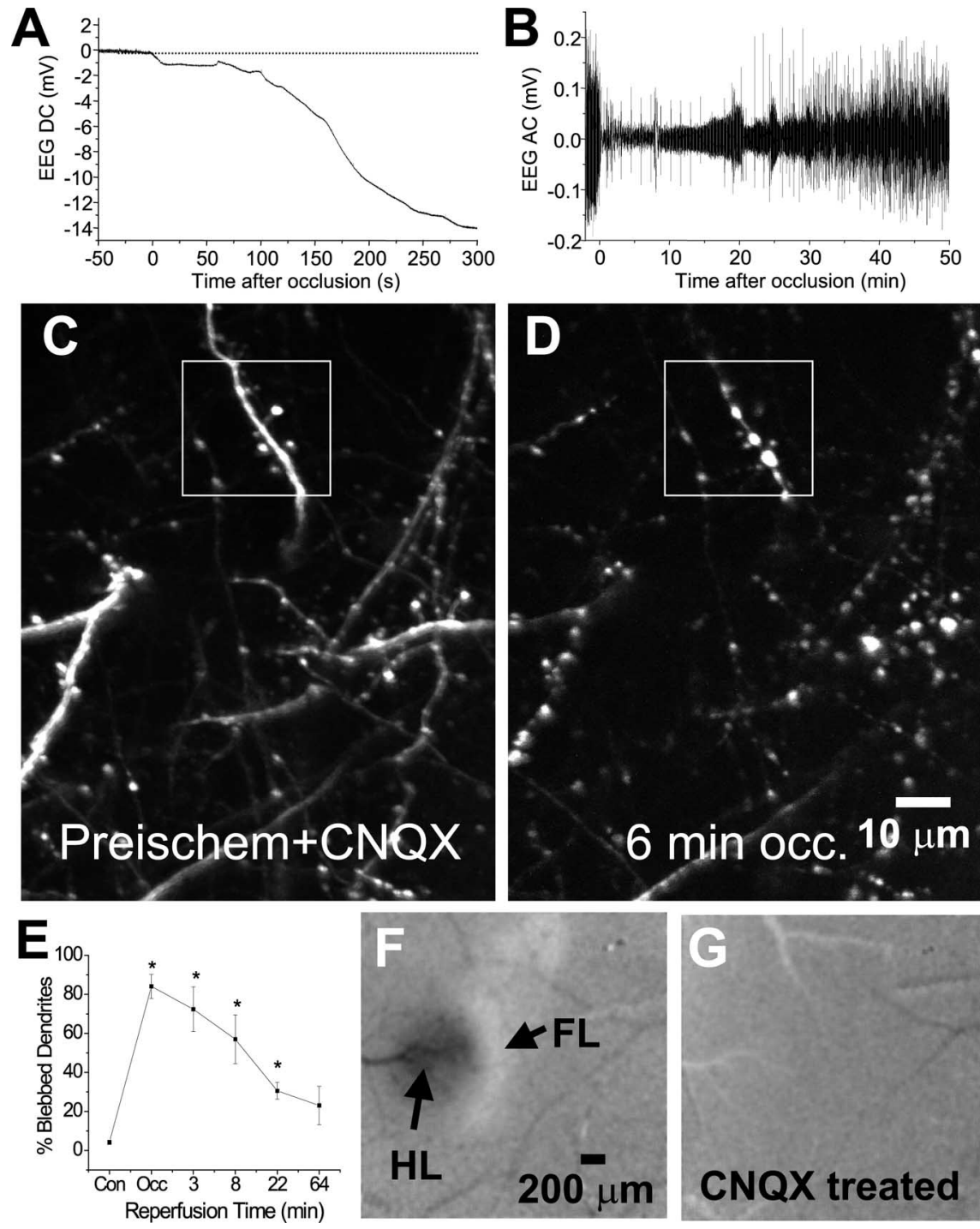

Figure 8. Antagonism of AMPA/kainate receptor activity fails to block ischemic depolarization or changes in morphology of dendrites $\boldsymbol{A}$, Ischemic depolarization assayed by a surface electrode occurs despite inclusion of $1 \mathrm{~mm}$ CNQX in the overlying agarose. $\boldsymbol{B}$, Reversible suppression of EEG activity in a CNQX-treated animal during bilateral CCA occlusion (DC record filtered at $0.1-10 \mathrm{~Hz}$ bandpass). C, Dendritic morphology preischemia and after 6 min of bilateral CCA occlusion (D).E, Group data on the percentage of blebbed dendrites preischemia and at the indicated times of reperfusion (data from $n=4$ animals; ${ }^{*} p<0.05$ one-way ANOVA). $\boldsymbol{F}$, Intrinsic optical signal map; for simplicity we have divided the hindlimb (HL) map by the forelimb (FL) map so activation in the hindlimb is coded by darker gray, whereas hindlimb activation is coded by lighter tones. The maps are the average of at least 30 stimulus trials. G, Application of CNQX completely blocked the maps in this and a total of three separate mice.

could be caused by neuronal activity in deeper brain regions. To assess whether evoked somatosensory stimulus-driven activity was antagonized by CNQX in three separate animals, we performed IOS mapping in response to stimuli given to the fore or hindlimb before and after CNQX treatment. In all three animals, the somatosensory maps were completely blocked by the CNQX, confirming that a sufficient local level of antagonist had been reached (Fig. $8 F, G$ ).

After establishing the efficacy of CNQX in vivo, we determined whether this treatment would affect ischemic depolarization or morphological changes caused by brief periods of global ischemia. The assessment of six animals indicated that ischemic depolarization was not significantly altered by CNQX treatment in amplitude $(10.9 \pm 1.1 \mathrm{mV})$ or latency $(131 \pm 17 \mathrm{~s})$, when compared with untreated controls. Furthermore, ischemia-induced loss of dendritic spines also still occurred in CNQX-treated ani- mals: $33 \pm 6 \%$ spine loss within $10 \mathrm{~min}$ of ischemic induction (data from seven ischemic episodes performed in five different animals). We also assessed dendritic blebbing in CNQX-treated animals and observed no significant reduction in blebbing despite antagonism of the AMPA receptor (four separate animals were quantified for the first stroke) (Fig. 8C-E). These findings when considered along with data using MK-801 suggest that early changes in dendritic morphology and ischemic depolarization can occur independently of ionotropic glutamate receptor activity. As a check that CNQX entry into the brain was not limiting in one animal, we completely removed the overlying dura, treated with CNQX, and still observed rapid changes in dendritic morphology at the time of ischemic onset (data not shown). To determine whether the CNQX effect was not overcome by the high glutamate concentrations present during ischemia we also treated three separate animals with $100 \mu \mathrm{M}$ GYKI 52466 and assessed dendritic blebbing in a similar manner to CNQXtreated animals and did not observe an apparent reduction. It is conceivable that this concentration of GYKI 52466 was insufficient to fully block AMPA receptors, but we were unable to use more concentrated solutions because of limitations in solubility. In GYKI-treated animals limb stimulation evoked IOS maps were still present (in five of five animals assessed) suggesting an insufficient block of AMPA receptors compared with CNQX (data not shown).

\section{Propagation of a global depolarization during global ischemia}

The timing of the ischemic depolarization observed during our EEG recordings indicated that it was similar to a spreading wave of depolarization previously shown to envelop brains subjected to global ischemia or injury in human clinical studies (Strong et al., 2002), rodents in vivo (Hossmann, 1996), and in vitro brain slices (Jarvis et al., 2001). To address this hypothesis, we performed IOS imaging during ischemia induction to examine the relationship between the observed EEG changes and waves of propagating depolarization. We relied on activity-induced changes in the $635 \mathrm{~nm}$ reflected light signal from the cortical surface as used by others to monitor ischemic depolarization or spreading depression (Pouratian and Toga, 2002; Chen et al., 2006; Brennan et al., 2007). Associated with ischemia was a darkening of the brain and major vessels that presumably reflects increased absorbance of cortical tissue (supplemental Movie 4, available at www.jneurosci.org as supplemental material), caused by relative deoxygenation of hemoglobin (Fig. 9). After $119 \pm 12 \mathrm{~s}$ of ischemia, we observed a spreading wave of increased light scattering moving across the cortex at a velocity of $55 \pm 10 \mu \mathrm{m} / \mathrm{s}(n=6$ animals, $\sim 3.3 \mathrm{~mm} / \mathrm{min})$, 

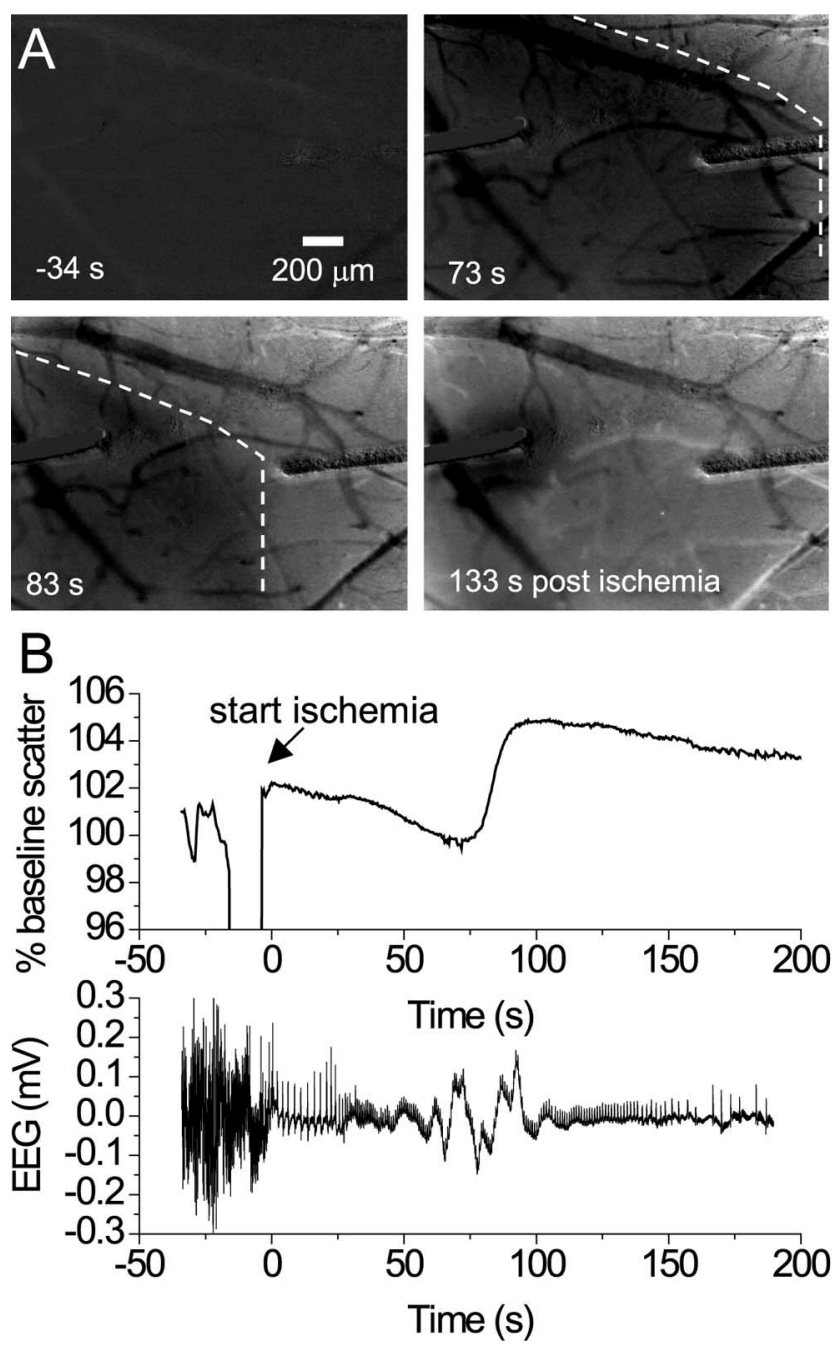

Figure 9. Waves of light scattering from the cortical surface signal ischemic depolarization during bilateral common carotid artery ligation. $\boldsymbol{A}$, The brain was illuminated with light from $635 \mathrm{~nm}$ LEDs and ratio images (images were divided by a preischemic baseline image) were created depicting changes in reflected light signal $-34,73$, and 83 s relative to ischemic onset. At the -34 s time point, a uniformly gray image is shown before ischemia indicating little regional difference in light scattering. The brightening of the image on the top right corner is a wave of increased light scattering that propagates across the cortex (from anterior lateral regions to medial posterior) during ischemic depolarization. $\boldsymbol{B}$, Quantification of changes in light scattering in the animal shown in $\boldsymbol{A}$ (made from an area of interest in the image center). The disruption in signal just before the start of ischemia is from handling the animal (blocking LEDs, $-30-0 \mathrm{~s}$ ). After carotid ligation and over the first $75 \mathrm{~s}$, there is a gradual darkening of the cortex and a reduction in reflected light signal. At $75 \mathrm{~s}$, the signal changes from a darkening to brightening and a wave of increased reflection spreads across the brain (upward deflection). In the bottom graph, the cortical EEG measured at the same time is plotted and indicates rapid EEG suppression during CCA ligation followed by a slow AC EEG ripple ( $A C$-filtered version of DC shift) that is coincident with the wave of light scattering.

similar to the velocity observed in brain slices (Andrew et al., 1999) and in vivo (Hossmann, 1996). This wave was well synchronized with slow AC-filtered changes on the cortical EEG that reflect ischemic depolarization (Fig. 9B). In all animals in which the wave was studied, we observed it to start as an increase in scattering (brighter image) from the most anterior and medial portions of the cortex and to spread posteriorly and laterally (supplemental Movie 4, available at www.jneurosci.org as supplemental material).

To determine whether the temporal relationship between ischemic depolarization and the observed changes in $\left[\mathrm{Ca}^{2+}\right]_{i}$ and dendritic structure was not merely fortuitous, we assessed whether the latencies (from ischemic onset) between ischemic depolarization and structural change, or $\left[\mathrm{Ca}^{2+}\right]$ elevation and structural change were correlated between multiple ischemic episodes. In the example in supplemental Figure 4 (available at www.jneurosci.org as supplemental material), the onset of ischemic depolarization varies by up to $60 \mathrm{~s}$ between two ischemic episodes (same animal), yet the latency to calcium elevation is within $10 \mathrm{~s}$. Analysis of group data indicated a tight temporal correlation $(r>0.95)$ (supplemental Fig. 6, available at www. jneurosci.org as supplemental material) between these values indicating that they are mechanistically linked, and that near coincidence between elevation in $\left[\mathrm{Ca}^{2+}\right]_{\mathrm{i}}$ and dendrite structural change is not by chance (a summary of the events associated with ischemia and reperfusion appears in Fig. 10).

\section{Discussion}

Global ischemia rapidly and reversibly alters cortical structure and function

Our results indicate that apical dendritic structure of layer $\mathrm{V}$ neurons is dramatically degraded within $\sim 2$ min of global ischemia. The loss of structure was coincident with a propagating wave of depolarization that spreads across the cortex producing elevations in $\left[\mathrm{Ca}^{2+}\right]_{\mathrm{i}}$ similar to those observed in vivo with permanent cardiac arrest or spreading depression (Chuquet et al., 2007; Takano et al., 2007). Contrary to the assumption that reperfusion would be associated with additional injury (Sugawara et al., 2004), for these brief periods of ischemia ( $\sim 7 \mathrm{~min})$, cortical structure, $\left[\mathrm{Ca}^{2+}\right]_{\mathrm{i}}$ levels, and somatosensory function were largely recovered after reperfusion. Regarding the physiological relevance of our findings, periods of ischemia sufficient to cause structural damage to dendrites would be encountered during cardiac arrest and resuscitation. However, the ability of brief ischemia $(\sim 2 \mathrm{~min})$ to cause structural alteration to dendrites suggest that common medical procedures such as bypass surgery that have brief interruptions in blood flow could lead to structural alteration of synapses. Indeed, forms of dementia are attributed to brief periods of cerebral ischemia associated with switching patients to temporary cardiac bypass (Roach et al., 1996; Stutz, 2003; Newman et al., 2004). Other conditions with brief recurrent ischemia would be chronic sleep apnea, as well as transient ischemia attack, both of which are associated with progressive vascular dementia (Roman, 2005).

\section{Relationship to selective neuronal loss in global ischemia models}

Most previous work in rodent global ischemia concerns the selective delayed death of hippocampal CA1 neurons triggered ischemia in excess of 10 min (Traystman, 2003; Yonekura et al., 2004). However, studies have also demonstrated delayed loss of C57BL/ 6 mouse cortical neurons caused by brief global ischemia using similar models (Olsson et al., 2003; Yonekura et al., 2004). It should be noted that most strains of mice will not undergo forebrain ischemia when subjected to bilateral CCA occlusion because they have redundant posterior pathways of circulation (Yang et al., 1997). The C57BL/6 mice we used typically lack posterior communicating arteries, allowing the effects of CCA occlusion to not be circumvented by posterior circulation.

Our observation of reversible changes in synaptic structure raises the question of whether similar events occur routinely during global ischemia in animal models. Studies indicate that during global ischemia in rodents, evoked synaptic activity is transiently suppressed (Gao et al., 1998), but can partially return within $24 \mathrm{~h}$ after reperfusion. Interestingly, seemingly 


\section{Ischemia structural and ionic mechanisms, in vivo timeline. (latencies)}

\section{Occlusion}

$<20$ s blockade of synaptic activity
$\sim 2-3$ min ischemic depolarization
$\sim 2-3$ min $\mathrm{Ca}^{2+}$ influx
$\sim 2-3$ min loss of synaptic structure.

\section{Reperfusion}

1-10 min intracellular $\mathrm{Ca}^{2+}$ levels declining
$\sim 4 \mathrm{~min}$ membrane potential regained
$4-30$ min synaptic structure regained
10-30 min synaptic activity returns (EEG)
$\sim 0.5-1 \mathrm{~h}$ somatosensory function returns
$0.75-2 \mathrm{~h}$ delayed membrane permeability
24-96 h possible cell death

Figure 10. Global ischemia structural and ionic mechanisms (in vivo timeline). Summary timeline for the first $2 \mathrm{~h}$ after $6-8$ min of global ischemia followed by reperfusion in layer I cortex.

recovered neurons with relatively normal synaptic properties (Gao et al., 1998) were lost to apoptosis days later. These results suggest that the reversible structural alterations we observe may act as, or accompany later apoptotic signals. Because structural changes can be reversible, it is conceivable that if effective neuroprotectants were developed, neurons with relatively normal synaptic structure could be saved. The relatively short occlusion times we used may also act as preconditioning signals that by themselves cause little neuronal loss, but protect against cell death after subsequent challenge with longer ischemia (Gidday, 2006; Stenzel-Poore et al., 2007). Previous histological studies suggest that brief periods of global ischemia (1.5 min) in gerbils can lead to an increase in hippocampal spine density and the development of ischemic preconditioning over a period of days (Corbett et al., 2006). Interestingly, over short $2 \mathrm{~h}$ time scales we found that dendritic damage was enhanced during a second ischemic episode indicating that rapid forms of preconditioning (PerezPinzon et al., 1999) may not occur in this system.

\section{Mechanism of propagated structural damage and depolarization}

Previous work indicates that ischemic depolarization is common in both focal and global stroke models (Hossmann, 1996, 2006). The mechanism of ischemic depolarization appears to be multifactorial and involves a combination of neurotransmitter release, receptor stimulation, and energy failure. Why ischemic depolarizing waves propagate across the cortex at regular velocity is not fully understood. Pharmacological intervention in a number of mechanisms have been only partially successful in stopping the wave, and notably the waves can still occur in the absence of NMDA receptor (NMDAR) activity in vitro (Jarvis et al., 2001) and in some studies in vivo (Xie et al., 1995). Consistent with this we find that the noncompetitive NMDAR antagonist MK-801 failed to block ischemic changes in dendritic structure, or rapid elevation in $\left[\mathrm{Ca}^{2+}\right]_{\mathrm{i}}$. Perhaps global ischemia studies showing neuroprotection with MK-801 (Lee et al., 1999; Hoyte et al., 2004) may have been attributed to its side effects such as hypothermia (Corbett et al., 1990). Post-treatment hypothermia (Nurse and Corbett, 1996) was also offered as an explanation for apparent neuroprotective effects of AMPA receptor antagonists in vivo (Sheardown et al., 1990; Buchan et al., 1991; Gaspary et al., 1994; Gressens et al., 2005), that we also fail to observe correlates of in our assays of acute dendritic changes. In the case of NMDA receptors, we do not rule out that in focal ischemia MK-801 may reduce aggravating factors such as periodic ischemic depolarizations that emanate from a site of ischemia increasing local metabolic demand, leading to further reductions in blood flow (Iijima et al., 1992; Hossmann, 1996, 2006; Shin et al., 2006). Although the detailed mechanism by which dendrites become damaged during ischemia is not complete, during the passage of ischemic depolarization extracellular $\mathrm{Ca}^{2+}$ concentration can fall by a factor of 10 (Kristian and Siesjo, 1998) as a result of massive intracellular ion uptake that can apparently occur in the absence of NMDAR activity. The coincident elevations in $\left[\mathrm{Ca}^{2+}\right]_{\mathrm{i}}$ and depolarization we observe are consistent with massive ion flux during ischemic depolarization. Although we show a tight temporal relationship between changes in $\left[\mathrm{Ca}^{2+}\right]_{i}$ and the loss of dendrite structure, it is conceivable that $\mathrm{Ca}^{2+}$-independent events such as $\mathrm{Cl}^{-}$and $\mathrm{Na}^{+}$redistribution may be also important in vivo, as observed in excitotoxin-induced dendritic beading in brain slices (Hoskison et al., 2007) and cell cultures (Hasbani et al., 1998). It is conceivable that after $\mathrm{Na}^{+}$and $\mathrm{Cl}^{-}$influx water may enter dendrites leading to blebbing. This idea is consistent with neurons undergoing a net water entry during anoxic depolarization (Andrew et al., 2007).

\section{What underlies the reversible change in dendritic structure during ischemia}

The trigger for ischemia-induced rapid deterioration of dendritic structure is clearly associated with the wave of depolarization and ion flux from its timing. However, what causes the dendrites to undergo such radical changes in structure is likely related to several factors at work. Studies indicate that dendritic blebbing can be caused by an anoxically triggered aggregation of cytoskeletal proteins, some of which are ubiquinated (Hu et al., 2001; Takeuchi et al., 2005), as well as a wave of mitochondrial depolarization (Greenwood et al., 2007). Electron microscopy of gerbil cortex after 5 min of global ischemia revealed swollen apical dendrites and mitochondria, as well as vacuole formation and disintegration of microtubules (Tomimoto and Yanagihara, 1992). In our images, dendritic blebs (that are likely the vacuoles seen in ultrastructure) are of larger volume than the areas between blebs, suggesting that blebs do not merely reflect a redistribution of XFP. In contrast, the regions between blebs appear to lose volume during ischemia. A loss of volume could be caused by compression by swollen components of adjacent cells. It is well documented that ischemic ion influxes trigger massive cell swelling characterized by a reduction in extracellular volume (Andrew et al., 1999; Hossmann, 2006). Interestingly, previous in vitro data indicate that neurons swell only mildly when depolarized, and only undergo blebbing when they are both ischemic and depolarized (Andrew et al., 2007). These findings would suggest that if the propagating ischemic depolarization we observe spread to areas with normal blood flow, it may not necessarily affect the structure of nonischemic neurons.

With regard to ischemia-induced optical artifacts causing spines to disappear and dendrites to bead, we believe that this is unlikely for a variety of reasons: small labeled vessels are still well resolved, both dendritic swelling and constrictions are observed (not merely blurring), and recovery of dendritic damage parallels neuronal function. Similar changes in structure can be produced in vitro using excitotoxins where imaging is less sensitive to environment (Hasbani et al., 2001; Ikegaya et al., 2001). In in vitro studies, spine loss was similar in 
neurons colabeled with both YFP and DiI, indicating that the effect is not unique to soluble XFP labeling (Hasbani et al., 2001). Data from investigators using in vitro ischemia, tissue cooling, and epilepsy support findings that spines can be reversibly altered (Hasbani et al., 2001; Kirov et al., 2004; Zeng et al., 2007). The ability of spines to disappear and reappear in the same locations could be attributed to detachment and reattachment of actin-based spines and their postsynaptic densities to the cytoskeleton (Schell and Irvine, 2006).

In summary, we provide evidence of rapid loss and recovery of spiny dendrite structure during brief global ischemia. Structural changes were not observed until a propagating wave of ischemic depolarization and $\left[\mathrm{Ca}^{2+}\right]_{\mathrm{i}}$ elevation occurred (Fig. 10). We hope that these data provide insight into the relative timing of events associated with damage to synaptic circuitry during ischemia, and help to guide therapeutic strategies that target mechanisms of ischemic depolarization, or benefit from reperfusion-induced recovery of synaptic structure and function.

\section{References}

Aarts M, Iihara K, Wei WL, Xiong ZG, Arundine M, Cerwinski W, MacDonald JF, Tymianski M (2003) A key role for TRPM7 channels in anoxic neuronal death. Cell 115:863-877.

Anderson TR, Jarvis CR, Biedermann AJ, Molnar C, Andrew RD (2005) Blocking the anoxic depolarization protects without functional compromise following simulated stroke in cortical brain slices. J Neurophysiol 93:963-979.

Andrew RD, Jarvis CR, Obeidat AS (1999) Potential sources of intrinsic optical signals imaged in live brain slices. Methods 18:185-196.

Andrew RD, Labron MW, Boehnke SE, Carnduff L, Kirov SA (2007) Physiological evidence that pyramidal neurons lack functional water channels. Cereb Cortex 17:787-802.

Appleton GO, Li Y, Taffet GE, Hartley CJ, Michael LH, Entman ML, Roberts R, Khoury DS (2004) Determinants of cardiac electrophysiological properties in mice. J Interv Card Electrophysiol 11:5-14.

Ayad M, Verity MA, Rubinstein EH (1994) Lidocaine delays cortical ischemic depolarization: relationship to electrophysiologic recovery and neuropathology. J Neurosurg Anesthesiol 6:98-110.

Biernaskie J, Corbett D, Peeling J, Wells J, Lei H (2001) A serial MR study of cerebral blood flow changes and lesion development following endothelin-1-induced ischemia in rats. Magn Reson Med 46:827-830.

Bonhoeffer T, Grinvald A (1993) Optical imaging of the functional architecture in cat visual cortex: the layout of direction and orientation domains. Adv Exp Med Biol 333:57-69.

Brennan KC, Beltran-Parrazal L, Lopez-Valdes HE, Theriot J, Toga AW, Charles AC (2007) Distinct vascular conduction with cortical spreading depression. J Neurophysiol 97:4143-4151.

Brown CE, Li P, Boyd JD, Delaney KR, Murphy TH (2007) Extensive turnover of dendritic spines and vascular remodeling in cortical tissues recovering from stroke. J Neurosci 27:4101-4109.

Buchan AM, Li H, Cho S, Pulsinelli WA (1991) Blockade of the AMPA receptor prevents $\mathrm{CA} 1$ hippocampal injury following severe but transient forebrain ischemia in adult rats. Neurosci Lett 132:255-258.

Chen S, Li P, Luo W, Gong H, Zeng S, Luo Q (2006) Origin sites of spontaneous cortical spreading depression migrated during focal cerebral ischemia in rats. Neurosci Lett 403:266-270.

Chuquet J, Hollender L, Nimchinsky EA (2007) High-resolution in vivo imaging of the neurovascular unit during spreading depression. J Neurosci 27:4036-4044

Contreras JE, Sanchez HA, Veliz LP, Bukauskas FF, Bennett MV, Saez JC (2004) Role of connexin-based gap junction channels and hemichannels in ischemia-induced cell death in nervous tissue. Brain Res Brain Res Rev 47:290-303.

Corbett D, Evans S, Thomas C, Wang D, Jonas RA (1990) MK-801 reduced cerebral ischemic injury by inducing hypothermia. Brain Res 514:300-304.

Corbett D, Giles T, Evans S, McLean J, Biernaskie J (2006) Dynamic changes in CA1 dendritic spines associated with ischemic tolerance. Exp Neurol 202:133-138.
Devor A, Dunn AK, Andermann ML, Ulbert I, Boas DA, Dale AM (2003) Coupling of total hemoglobin concentration, oxygenation, and neural activity in rat somatosensory cortex. Neuron 39:353-359.

Diemer NH, Jorgensen MB, Johansen FF, Sheardown M, Honore T (1992) Protection against ischemic hippocampal CA1 damage in the rat with a new non-NMDA antagonist, NBQX. Acta Neurol Scand 86:45-49.

Du C, Koretsky AP, Izrailtyan I, Benveniste H (2005) Simultaneous detection of blood volume, oxygenation, and intracellular calcium changes during cerebral ischemia and reperfusion in vivo using diffuse reflectance and fluorescence. J Cereb Blood Flow Metab 25:1078-1092.

Dunn AK, Devor A, Dale AM, Boas DA (2005) Spatial extent of oxygen metabolism and hemodynamic changes during functional activation of the rat somatosensory cortex. NeuroImage 27:279-290.

Elfgang C, Eckert R, Lichtenberg-Frate H, Butterweck A, Traub O, Klein RA, Hulser DF, Willecke K (1995) Specific permeability and selective formation of gap junction channels in connexin-transfected HeLa cells. J Cell Biol 129:805-817.

Feng G, Mellor RH, Bernstein M, Keller-Peck C, Nguyen QT, Wallace M, Nerbonne JM, Lichtman JW, Sanes JR (2000) Imaging neuronal subsets in transgenic mice expressing multiple spectral variants of GFP. Neuron 28:41-51.

Ferezou I, Bolea S, Petersen CC (2006) Visualizing the cortical representation of whisker touch: voltage-sensitive dye imaging in freely moving mice. Neuron 50:617-629.

Gao TM, Pulsinelli WA, Xu ZC (1998) Prolonged enhancement and depression of synaptic transmission in CA1 pyramidal neurons induced by transient forebrain ischemia in vivo. Neuroscience 87:371-383.

Gaspary HL, Simon RP, Graham SH (1994) BW1003C87 and NBQX but not CGS19755 reduce glutamate release and cerebral ischemic necrosis. Eur J Pharmacol 262:197-203.

Gidday JM (2006) Cerebral preconditioning and ischaemic tolerance. Nat Rev Neurosci 7:437-448.

Greenwood SM, Mizielinska SM, Frenguelli BG, Harvey J, Connolly CN (2007) Mitochondrial dysfunction and dendritic beading during neuronal toxicity. J Biol Chem 282:26235-26244.

Gressens P, Spedding M, Gigler G, Kertesz S, Villa P, Medja F, Williamson T, Kapus G, Levay G, Szenasi G, Barkoczy J, Harsing Jr LG (2005) The effects of AMPA receptor antagonists in models of stroke and neurodegeneration. Eur J Pharmacol 519:58-67.

Griesbeck O, Baird GS, Campbell RE, Zacharias DA, Tsien RY (2001) Reducing the environmental sensitivity of yellow fluorescent protein. Mechanism and applications. J Biol Chem 276:29188-29194.

Grinvald A, Hildesheim R (2004) VSDI: a new era in functional imaging of cortical dynamics. Nat Rev Neurosci 5:874-885.

Gurden H, Uchida N, Mainen ZF (2006) Sensory-evoked intrinsic optical signals in the olfactory bulb are coupled to glutamate release and uptake. Neuron 52:335-345.

Hasbani MJ, Hyrc KL, Faddis BT, Romano C, Goldberg MP (1998) Distinct roles for sodium, chloride, and calcium in excitotoxic dendritic injury and recovery. Exp Neurol 154:241-258.

Hasbani MJ, Schlief ML, Fisher DA, Goldberg MP (2001) Dendritic spines lost during glutamate receptor activation reemerge at original sites of synaptic contact. J Neurosci 21:2393-2403.

Hori N, Carpenter DO (1994) Functional and morphological changes induced by transient in vivo ischemia. Exp Neurol 129:279-289.

Hoskison MM, Yanagawa Y, Obata K, Shuttleworth CW (2007) Calciumdependent NMDA-induced dendritic injury and MAP2 loss in acute hippocampal slices. Neuroscience 145:66-79.

Hossmann KA (1996) Periinfarct depolarizations. Cerebrovasc Brain Metab Rev 8:195-208.

Hossmann KA (2006) Pathophysiology and therapy of experimental stroke. Cell Mol Neurobiol 26:1057-1083.

Hoyte L, Barber PA, Buchan AM, Hill MD (2004) The rise and fall of NMDA antagonists for ischemic stroke. Curr Mol Med 4:131-136.

Hu BR, Janelidze S, Ginsberg MD, Busto R, Perez-Pinzon M, Sick TJ, Siesjo BK, Liu CL (2001) Protein aggregation after focal brain ischemia and reperfusion. J Cereb Blood Flow Metab 21:865-875.

Iijima T, Mies G, Hossmann KA (1992) Repeated negative DC deflections in rat cortex following middle cerebral artery occlusion are abolished by MK-801: effect on volume of ischemic injury. J Cereb Blood Flow Metab 12:727-733.

Ikegaya Y, Kim JA, Baba M, Iwatsubo T, Nishiyama N, Matsuki N (2001) Rapid and reversible changes in dendrite morphology and synaptic effi- 
cacy following NMDA receptor activation: implication for a cellular defense against excitotoxicity. J Cell Sci 114:4083-4093.

Jarvis CR, Anderson TR, Andrew RD (2001) Anoxic depolarization mediates acute damage independent of glutamate in neocortical brain slices. Cereb Cortex 11:249-259.

Joshi I, Andrew RD (2001) Imaging anoxic depolarization during ischemia-like conditions in the mouse hemi-brain slice. J Neurophysiol 85:414-424.

Kaminogo M, Suyama K, Ichikura A, Onizuka M, Shibata S (1998) Anoxic depolarization determines ischemic brain injury. Neurol Res 20:343-348.

Kastrup A, Neumann-Haefelin T, Moseley ME, de Crespigny A (2000) High speed diffusion magnetic resonance imaging of ischemia and spontaneous periinfarct spreading depression after thromboembolic stroke in the rat. J Cereb Blood Flow Metab 20:1636-1647.

Kerr JN, Greenberg D, Helmchen F (2005) Imaging input and output of neocortical networks in vivo. Proc Natl Acad Sci USA 102:14063-14068.

Kirov SA, Petrak LJ, Fiala JC, Harris KM (2004) Dendritic spines disappear with chilling but proliferate excessively upon rewarming of mature hippocampus. Neuroscience 127:69-80.

Kleinfeld D, Mitra PP, Helmchen F, Denk W (1998) Fluctuations and stimulusinduced changes in blood flow observed in individual capillaries in layers 2 through 4 of rat neocortex. Proc Natl Acad Sci USA 95:15741-15746.

Kristian T, Siesjo BK (1998) Calcium in ischemic cell death. Stroke 29:705-718.

Lee JM, Zipfel GJ, Choi DW (1999) The changing landscape of ischaemic brain injury mechanisms. Nature 399:A7-A14.

Li J, Takeda Y, Hirakawa M (2000) Threshold of ischemic depolarization for neuronal injury following four-vessel occlusion in the rat cortex. J Neurosurg Anesthesiol 12:247-254.

Nedergaard M, Hansen AJ (1993) Characterization of cortical depolarizations evoked in focal cerebral ischemia. J Cereb Blood Flow Metab 13:568-574.

Newman MF, Blumenthal JA, Mark DB (2004) Fixing the heart: must the brain pay the price? Circulation 110:3402-3403.

Nimmerjahn A, Kirchhoff F, Kerr JN, Helmchen F (2004) Sulforhodamine 101 as a specific marker of astroglia in the neocortex in vivo. Nat Methods $1: 31-37$.

Nishimura N, Schaffer CB, Friedman B, Tsai PS, Lyden PD, Kleinfeld D (2006) Targeted insult to subsurface cortical blood vessels using ultrashort laser pulses: three models of stroke. Nat Methods 3:99-108.

Nurse S, Corbett D (1996) Neuroprotection after several days of mild, druginduced hypothermia. J Cereb Blood Flow Metab 16:474-480.

Ohki K, Chung S, Ch'ng YH, Kara P, Reid RC (2005) Functional imaging with cellular resolution reveals precise micro-architecture in visual cortex. Nature 433:597-603.

Olsson T, Wieloch T, Smith ML (2003) Brain damage in a mouse model of global cerebral ischemia. Effect of NMDA receptor blockade. Brain Res 982:260-269.

Park JS, Bateman MC, Goldberg MP (1996) Rapid alterations in dendrite morphology during sublethal hypoxia or glutamate receptor activation. Neurobiol Dis 3:215-227.

Perez-Pinzon MA, Vitro TM, Dietrich WD, Sick TJ (1999) The effect of rapid preconditioning on the microglial, astrocytic and neuronal consequences of global cerebral ischemia. Acta Neuropathol (Berl) 97:495-501.

Pouratian N, Toga AW (2002) Optical imaging based on intrinsic signals. In: Brain mapping: the methods, Ed 2. San Diego: Academic.

Roach GW, Kanchuger M, Mangano CM, Newman M, Nussmeier N, Wolman R, Aggarwal A, Marschall K, Graham SH, Ley C (1996) Adverse cerebral outcomes after coronary bypass surgery. Multicenter study of Perioperative Ischemia Research Group and the Ischemia Research and Education Foundation Investigators. $\mathrm{N}$ Engl J Med 335:1857-1863.

Roman GC (2005) Vascular dementia prevention: a risk factor analysis. Cerebrovasc Dis 20 [Suppl 2]:91-100.

Schaffer CB, Friedman B, Nishimura N, Schroeder LF, Tsai PS, Ebner FF, Lyden PD, Kleinfeld D (2006) Two-photon imaging of cortical surface microvessels reveals a robust redistribution in blood flow after vascular occlusion. PLoS Biol 4:e22.

Schell MJ, Irvine RF (2006) Calcium-triggered exit of F-actin and $\operatorname{IP(3)}$ 3 -kinase A from dendritic spines is rapid and reversible. Eur J Neurosci 24:2491-2503.

Sheardown MJ, Nielsen EO, Hansen AJ, Jacobsen P, Honore T (1990) 2,3-
Dihydroxy-6-nitro-7-sulfamoyl-benzo(F)quinoxaline: a neuroprotectant for cerebral ischemia. Science 247:571-574.

Sheardown MJ, Suzdak PD, Nordholm L (1993) AMPA, but not NMDA, receptor antagonism is neuroprotective in gerbil global ischaemia, even when delayed $24 \mathrm{~h}$. Eur J Pharmacol 236:347-353.

Shin HK, Dunn AK, Jones PB, Boas DA, Moskowitz MA, Ayata C (2006) Vasoconstrictive neurovascular coupling during focal ischemic depolarizations. J Cereb Blood Flow Metab 26:1018-1030.

Shoham D, Glaser DE, Arieli A, Kenet T, Wijnbergen C, Toledo Y, Hildesheim R, Grinvald A (1999) Imaging cortical dynamics at high spatial and temporal resolution with novel blue voltage-sensitive dyes. Neuron 24:791-802.

Silver IA, Erecinska M (1990) Intracellular and extracellular changes of $\left[\mathrm{Ca}^{2+}\right]$ in hypoxia and ischemia in rat brain in vivo. J Gen Physiol 95:837-866.

Silver IA, Erecinska M (1992) Ion homeostasis in rat brain in vivo: intra- and extracellular $\left[\mathrm{Ca}^{2+}\right]$ and $[\mathrm{H}+]$ in the hippocampus during recovery from short-term, transient ischemia. J Cereb Blood Flow Metab 12:759-772.

Simon RP (2006) Acidotoxicity trumps excitotoxicity in ischemic brain. Arch Neurol 63:1368-1371.

Stenzel-Poore MP, Stevens SL, King JS, Simon RP (2007) Preconditioning reprograms the response to ischemic injury and primes the emergence of unique endogenous neuroprotective phenotypes: a speculative synthesis. Stroke 38:680-685.

Stosiek C, Garaschuk O, Holthoff K, Konnerth A (2003) In vivo two-photon calcium imaging of neuronal networks. Proc Natl Acad Sci USA 100:7319-7324.

Strong AJ, Fabricius M, Boutelle MG, Hibbins SJ, Hopwood SE, Jones R, Parkin MC, Lauritzen M (2002) Spreading and synchronous depressions of cortical activity in acutely injured human brain. Stroke 33:2738-2743.

Stutz B (2003) Pumphead. Sci Am 289:76-81.

Sugawara T, Fujimura M, Noshita N, Kim GW, Saito A, Hayashi T, Narasimhan P, Maier CM, Chan PH (2004) Neuronal death/survival signaling pathways in cerebral ischemia. NeuroRx 1:17-25.

Sun X, Shih AY, Johannssen HC, Erb H, Li P, Murphy TH (2006) Twophoton imaging of glutathione levels in intact brain indicates enhanced redox buffering in developing neurons and cells at the cerebrospinal fluid and blood-brain interface. J Biol Chem 281:17420-17431.

Takano T, Tian GF, Peng W, Lou N, Lovatt D, Hansen AJ, Kasischke KA, Nedergaard M (2007) Cortical spreading depression causes and coincides with tissue hypoxia. Nat Neurosci 10:754-762.

Takeuchi H, Mizuno T, Zhang G, Wang J, Kawanokuchi J, Kuno R, Suzumura A (2005) Neuritic beading induced by activated microglia is an early feature of neuronal dysfunction toward neuronal death by inhibition of mitochondrial respiration and axonal transport. J Biol Chem 280:10444-10454.

Thompson RJ, Zhou N, MacVicar BA (2006) Ischemia opens neuronal gap junction hemichannels. Science 312:924-927.

Tomimoto H, Yanagihara T (1992) Electron microscopic investigation of the cerebral cortex after cerebral ischemia and reperfusion in the gerbil. Brain Res 598:87-97.

Traystman RJ (2003) Animal models of focal and global cerebral ischemia. Ilar J 44:85-95.

Wang X, Lou N, Xu Q, Tian GF, Peng WG, Han X, Kang J, Takano T, Nedergaard M (2006) Astrocytic $\mathrm{Ca}^{2+}$ signaling evoked by sensory stimulation in vivo. Nat Neurosci 9:816-823.

Winship IR, Plaa N, Murphy TH (2007) Rapid astrocyte calcium signals correlate with neuronal activity and onset of the hemodynamic response in vivo. J Neurosci 27:6268-6272.

Xie Y, Zacharias E, Hoff P, Tegtmeier F (1995) Ion channel involvement in anoxic depolarization induced by cardiac arrest in rat brain. J Cereb Blood Flow Metab 15:587-594.

Xiong ZG, Zhu XM, Chu XP, Minami M, Hey J, Wei WL, MacDonald JF, Wemmie JA, Price MP, Welsh MJ, Simon RP (2004) Neuroprotection in ischemia: blocking calcium-permeable acid-sensing ion channels. Cell 118:687-698.

Yang G, Kitagawa K, Matsushita K, Mabuchi T, Yagita Y, Yanagihara T, Matsumoto M (1997) C57BL/6 strain is most susceptible to cerebral ischemia following bilateral common carotid occlusion among seven mouse strains: selective neuronal death in the murine transient forebrain ischemia. Brain Res 752:209-218. 
Yonekura I, Kawahara N, Nakatomi H, Furuya K, Kirino T (2004) A model of global cerebral ischemia in C57 BL/6 mice. J Cereb Blood Flow Metab 24:151-158.

Zeng LH, Xu L, Rensing NR, Sinatra PM, Rothman SM, Wong M (2007) Kainate seizures cause acute dendritic injury and actin depolymerization in vivo. J Neurosci 27:11604-11613.
Zhang S, Murphy TH (2007) Imaging the impact of cortical microcirculation on synaptic structure and sensory-evoked hemodynamic responses in vivo. PLoS Biol 5:e119.

Zhang S, Boyd J, Delaney K, Murphy TH (2005) Rapid reversible changes in dendritic spine structure in vivo gated by the degree of ischemia. J Neurosci 25:5333-5338. 